\title{
Cell Wall Anchoring of the Campylobacter Antigens to Lactococcus lactis
}

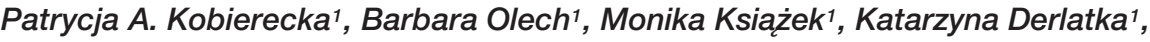 \\ Iwona Adamska' ${ }^{2}$ Paweł M. Majewski ${ }^{2}$, Elżbieta K. Jagusztyn-Krynicka ${ }^{1}$ and \\ Agnieszka K. Wyszyńska ${ }^{\text {* }}$ \\ ${ }^{1}$ Department of Bacterial Genetics, Institute of Microbiology, Faculty of Biology, University of Warsaw, Warsaw, Poland, \\ ${ }^{2}$ Department of Animal Physiology, Institute of Zoology, Faculty of Biology, University of Warsaw, Warsaw, Poland
}

Campylobacter jejuni is the most frequent cause of human food-borne gastroenteritis and chicken meat is the main source of infection. Recent studies showed that broiler chicken immunization against Campylobacter should be the most efficient way to lower the number of human infections by this pathogen. Induction of the mucosal immune system after oral antigen administration should provide protective immunity to chickens. In this work we tested the usefulness of Lactococcus lactis, the most extensively studied lactic acid bacterium, as a delivery vector for Campylobacter antigens. First we constructed hybrid protein - CjaA antigen presenting CjaD peptide epitopes on its surface. We showed that specific rabbit anti-rCjaAD serum reacted strongly with both $\mathrm{CjaA}$ and $\mathrm{CjaD}$ produced by a wild type C. jejuni strain. Next, rCjaAD and CjaA were fused to the C-terminus of the L. lactis YndF containing the LPTXG motif. The genes expressing these proteins were transcribed under control of the L. lactis Usp45 promoter and their products contain the Usp45 signal sequences. This strategy ensures a cell surface location of both analyzed proteins, which was confirmed by immunofluorescence assay. In order to evaluate the impact of antigen location on vaccine prototype efficacy, a $L$. lactis strain producing cytoplasm-located rCjaAD was also generated. Animal experiments showed a decrease of Campylobacter cecal load in vaccinated birds as compared with the control group and showed that the $L$. lactis harboring the surface-exposed $r C j a A D$ antigen afforded greater protection than the $L$. lactis producing cytoplasm-located rCjaAD. To the best of our knowledge, this is the first attempt to employ Lactic Acid Bacteria $(L A B)$ strains as a mucosal delivery vehicle for chicken immunization. Although the observed reduction of chicken colonization by Campylobacter resulting from vaccination was rather moderate, the experiments showed that LAB strains can be considered as an alternative vector to deliver heterologous antigens to the bird immune system. Additionally, the analysis of the structure and immunogenicity of the generated rCjaAD hybrid protein showed that the CjaA antigen can be considered as a starting point to construct multiepitope anti-Campylobacter vaccines.

Keywords: Lactococcus lactis, LPXTG cell wall anchor domain, Campylobacter, vaccine, chicken immunization 


\section{INTRODUCTION}

Campylobacter sp., members of Epsilonproteobacteria, are intestinal inhabitants of a various animal and avian species and, at the same time, are a major cause of human bacterial food-borne gastroenteritis; each year they are responsible for several 100 million cases of infection worldwide. The number of reported confirmed cases of human campylobacteriosis varies between countries and ranges between ten to more than 100 per 100,000 population (Kaakoush et al., 2015). In the EU in 2013, 214,779 cases were recorded (EFSA and ECDC, 2015). The number of Campylobacter genus species is growing constantly. Among at least 34 (http://www.bacterio.net/campylobacter.html \%20consulted\%20on\%2001/2016) species of the Campylobacter genus which have been described so far, the most prevalent species isolated from clinical cases of human campylobacteriosis are C. jejuni and C. coli (Robyn et al., 2015). Whereas in developing countries, the disease is endemic and affects mainly children, in industrialized countries most cases of the disease are mainly sporadic and are caused by the consumption of pathogen-contaminated, improperly prepared broiler meat. The gastrointestinal tract of infected broiler chickens contains a very high load of C. jejuni (Silva et al., 2011; Hermans et al., 2012; Powell et al., 2012). So, taking into consideration the broad consumption of poultry meat products, it has been established that the chicken reservoir is the main source of human campylobacteriosis. It was calculated that decreasing the count of Campylobacter in chicken intestines by $2 \log _{10}$-units would lower the number of human campylobacteriosis cases 30 -fold, and that a reduction by 3 log units should diminish the public health risk by at least 90\% (EFSA Panel on Biological Hazards (BIOHAZ), 2011; Rosenquist et al., 2013).

Reduction of chicken colonization by Campylobacter can be achieved by vaccination, but an effective chicken vaccine against Campylobacter is still lacking. To date, many Campylobacter immunogenic proteins have been identified and tested as protective antigens in chicken animal models using various delivery vehicles and immunization strategies, but only with partial success. The induction of immune responses (specific intestinal IgA and serum $\operatorname{IgG}$ ) was documented as a result of immunizations, but the generated reductions of chicken intestinal track colonization by $C$. jejuni were not satisfactory (Wyszyńska et al., 2004; Buckley et al., 2010; Layton et al., 2011; Clark et al., 2012; Neal-McKinney et al., 2012; Theoret et al., 2012) also reviewed in references (de Zoete et al., 2007; JagusztynKrynicka et al., 2009).

The current knowledge indicates that an effective chicken vaccine should induce both a strong and rapid immune response, due to the short life span of broiler chickens. For a short time after hatching, the chicks are protected against Campylobacter infection by a high level of maternal antibodies. The mechanism of this protection is not completely clear (Sahin et al., 2001; Sahin et al., 2003; Cawthraw and Newell, 2010). Therefore, birds should be immunized during the first week of life, when the avian immune system is immature. Given this aspect of immunization, we have to deepen our knowledge about Campylobacter factors involved in chicken colonization, as well as the pathogen's interaction with the bird's immune system (Hermans et al., 2011a). Additionally, with the advances in sequencing technologies, it becomes obvious that the development of a universal effective chicken vaccine against Campylobacter is hampered by the Campylobacter genome plasticity and antigenic complexity (Friis et al., 2010; Jeon et al., 2010; Gilbreath et al., 2011; Meric et al., 2014). The genetic diversity among Campylobacter strains finds reflection in chicken infection biology (Chaloner et al., 2014). Additionally, epidemiological studies indicate that there are multiple Campylobacter strains present in broiler flocks at the same time (Newell et al., 2010). So, it is generally thought that only multicomponent subunit vaccines, or using various preparations for the primary vaccination and for the booster, will satisfy immunization requirements.

Recently, the three-dimensional (3D) structures of many antigens have been resolved using mainly two technologies: nuclear magnetic resonance (NMR) spectroscopy and X-ray crystallography, which in combination with bioinformatics strategies allow mapping of the antigen epitopes and can initiate the development of structural vaccinology. This strategy should overcome several limitations in the development of vaccines to protect against pathogens with genetic diversity or antigenic hypervariability (Delany et al., 2014). The first vaccine generated by employing technologies of reverse and structural vaccinology is the $4 \mathrm{CMenB}$ multicomponent vaccine against serogroup Neisseria meningitidis approved in 2013 by the European Medicine Agency (Serruto et al., 2012).

In this study, we designed and constructed a hybrid CjaA antigen, named the $\mathrm{rCjaAD}$ protein, that displays three $\mathrm{CjaD}$ peptide epitopes on its surface. Next, the gene encoding rCjaAD was cloned into a L. lactis strain in a way that ensured the location of its product to the cell surface. The constructed strain was used for chicken immunization to evaluate the induced immune response and the protective effect of immunization.

\section{MATERIALS AND METHODS}

\section{Bacterial Strains, Primers, Plasmids, Media and Growth Conditions}

Bacterial strains, plasmids and primers used in this study are listed in Tables 1 and 2. The L. lactis IL1403 strain used in this study was routinely cultured at $30^{\circ} \mathrm{C}$ in M17 broth (Oxoid) containing $0.5 \%$ (wt/vol) glucose (GM17). When needed, media were supplemented with $5 \mu \mathrm{g} \mathrm{ml} \mathrm{ml}^{-1}$ erythromycin. The Escherichia coli strain TG1 was used as a host for the construction of recombinant plasmids. The E. coli strain Rosetta (DE3) pLysS was used to overproduce rCjaAD (pUWM1379). E. coli strains were grown under standard conditions unless otherwise indicated. When needed, media were supplemented with antibiotics at the following concentrations: $30 \mu \mathrm{g} \mathrm{ml}^{-1}$ kanamycin, $250 \mu \mathrm{g} \mathrm{ml} \mathrm{m}^{-1}$ erythromycin, or $20 \mu \mathrm{g} \mathrm{ml} \mathrm{m}^{-1}$ chloramphenicol. C. jejuni strain 81-176 was the source of the cjaA (cjj81176_1001, cj0982c) gene. C. jejuni 12/2 strain employed in the protection experiment was a broiler-isolated strain labeled with the pUOA18 plasmid containing a cat 
TABLE 1 | Bacterial strains and plasmids used in this study.

\begin{tabular}{|c|c|c|}
\hline Strain or plasmid & Relevant phenotype(s) or genotype(s) & Source or reference \\
\hline \multicolumn{3}{|l|}{ Strains } \\
\hline L. lactis subsp. lactis IL1403 & Plasmid-free strain & INRA (Chopin et al., 1984) \\
\hline E. coli TG1 & $\begin{array}{l}\text { supE thi-1 } \Delta\left(\text { lac-proAB) } \Delta(m c r B-h s d S M) 5\left(r K^{-} m K^{-}\right) F^{\prime}[\text { traD36 proAB+laclq }\right. \\
\text { lacZ_M15] }\end{array}$ & Sambrook and Russell, 2001 \\
\hline E. coli Rosetta pLysS (DE3) & $\mathrm{F}^{-}$ompt hsd $\mathrm{B}_{\mathrm{B}}\left(\mathrm{r}_{\mathrm{B}}^{-} \mathrm{m}_{\mathrm{B}}^{-}\right) \mathrm{gal} \mathrm{dcm}(\mathrm{DE} 3)$ pLysSRARE $\left(\mathrm{Cm}^{\mathrm{R}}\right)$ & Novagen \\
\hline C. jejuni 81176 & $\begin{array}{l}\text { Wild type; isolated from a child with bloody diarrhea during an outbreak in } \\
\text { Minnesota (USA); pVir, pTet }\left(\operatorname{Tc}^{R}\right) \text {; Lior 5; Penner } 23 / 26\end{array}$ & Korlath et al., 1985 \\
\hline C. jejuni $12 / 2$ & Wild type; isolated from a chicken; good colonizer; pUOA18 $\left(\mathrm{Cm}^{\mathrm{R}}\right)$ & Wyszyńska et al., 2004 \\
\hline \multicolumn{3}{|l|}{ Plasmids } \\
\hline pGEM-T Easy & $A p^{R} ;$ T vector for cloning PCR products & Promega \\
\hline pET28a & $\mathrm{Km}^{\mathrm{R}}$; lacl; overexpression vector & Novagen \\
\hline pBluescript II SK+ & $A p^{R}$; general cloning vector & Stratagene \\
\hline plL253 & $\mathrm{Em}^{\mathrm{R}}$, lactococcal cloning vector & Simon and Chopin, 1988 \\
\hline pUWM1000 & $\mathrm{Em}^{\mathrm{R}}$, L. lactis /E. coli shuttle vector (plL253 containing ori pBR322) & This study \\
\hline pUWM1371 & $\operatorname{rcjaAD}$ in Bluescript II SK+ & This study \\
\hline pUWM1379 & 6xhis-rcjaAD-6xhis fusion in pET28a & This study \\
\hline pUWM1373 & Fragment encoding signal sequence of Usp45 (ss $\left.s_{\text {usp45}}\right)$ in pGEM-T easy & This study \\
\hline pUWM1376 & $\begin{array}{l}\text { Fragment encoding C-terminal CWA region of YndF (LPXTGYnd) in pGEM-T } \\
\text { easy }\end{array}$ & This study \\
\hline pUWM1381 & $\begin{array}{l}\text { Fragment encoding signal sequence of Usp45 (ssusp45) and fragment encoding } \\
\text { C-terminal CWA region of YndF (LPXTGYnd) in pBluescript II SK }\end{array}$ & This study \\
\hline pUWM1384 & sS usp45_cjaA_LPXTGYndF in pBluescript II SK & This study \\
\hline pUWM1392 & SS usp45_rcjaAD_LPXTGYndF in pUWM1000 & This study \\
\hline pUWM1395 & 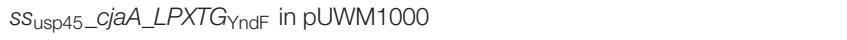 & This study \\
\hline pUWM1412 & rcjaAD in pUWM1000 & This study \\
\hline
\end{tabular}

TABLE 2 | Oligonucleotides used in this study.

\begin{tabular}{|c|c|c|}
\hline Name of primer & Sequence* & Restriction recognition sites \\
\hline UspAx & agaggtaccgaattcTGTTTACCAGCTAGCGCCTA & Kpnl, EcoRl \\
\hline UspBx & atggcgcatgccgggcccaaTGAATTTGTGTCAGCGTAGA & Sph, Apal \\
\hline UspCx & 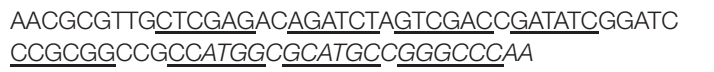 & $\begin{array}{l}\text { Mlul, Xhol, Bglll, Sall, EcoRV, } \\
\text { BamHI, Sacll, Ncol, Sphl, Apal }\end{array}$ \\
\hline UspDx & TATATCGATAACGCGTTGCTCGAGACAGA & Clal \\
\hline YhgE_Clal_LPXTG & taatcgataGGCTTGAACTTGGTTGATAA & Clal \\
\hline YhgE_Xbal & agttctagagaattccaGCCATCATCCCСTCCTAA & Xbal, EcoRl \\
\hline YndF_Clal_LPXTG & ttaatcgaTTGGTAATGCCTCTGGCCAAT & Clal \\
\hline YndF_Xbal_LPXTG & agttctagagaaTTCCACAACCATTGCCССТCСTTT & Xbal, EcoRl \\
\hline 1001_Xho_LPXTG & acctcgagtcAATTTTTCCACCTTCAATCAC & Xhol \\
\hline 1001_Bam_LPXTG & acaggatccGGAGGAAATTCTGACTC & $\mathrm{BamHI}$ \\
\hline R_CjaAD_inF & agatccccgggaattcttaAATTTTTCCACСТTCAATCAC & EcoRl \\
\hline F_CjaAD_inF & tgattaaatagaattcAGGAATTGTATGGGAGGAAATTCTGACGAAG & EcoRl \\
\hline
\end{tabular}

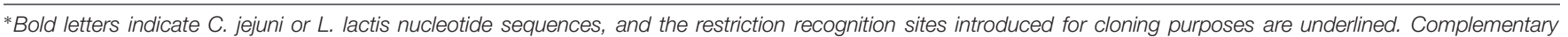
fragments of primers UspBx + UspCx and UspCx + UspDx are marked with italics. Primers were based on the C. jejuni 81176 or L. lactis IL1403 nucleotide sequences.

gene. Previous experiments have shown that the pUOA18 plasmid is stably maintained in Campylobacter (Wyszyńska et al., 2004). C. jejuni strains were routinely grown at $37^{\circ} \mathrm{C}$ or $42^{\circ} \mathrm{C}$ for $16-24 \mathrm{~h}$ under microaerobic conditions $(5 \%$ $\mathrm{O}_{2}, 10 \% \mathrm{CO}_{2}, 85 \% \mathrm{~N}_{2}$ ) on Blood Agar Base No. 2 (BA, Merck, Darmstadt, Germany) plates supplemented with 5\% horse blood and "Campylobacter Selective Supplement (Blaser-Wang)" (Oxoid, Basingstoke, UK). The medium was supplemented with chloramphenicol (15 $\left.\mu \mathrm{g} \mathrm{ml} \mathrm{ml}^{-1}\right)$, if necessary.

\section{DNA Manipulations}

\section{General DNA Manipulations}

Standard DNA manipulations were carried out as described earlier by Sambrook and Russell (2001) or according to the manufacturer's instructions (A\&A Biotechnology, Poland). Chromosomal DNAs of C. jejuni 81-176 and L. lactis used for PCR reactions were isolated using a commercial kit and protocol (A\&A Biotechnology, Poland). Polymerase chain reactions (PCRs) were performed with PrimeStar HS DNA Polymerase 
(TaKaRa) or HotStar HiFidelity Polymerase (Qiagen) under standard conditions. Synthetic oligonucleotide synthesis and DNA sequencing for cloning experiments were performed by Genomed S.A., Warsaw.

\section{Construction of Recombinant Plasmids for Recombinant Protein Overexpression}

A DNA fragment encoding rCjaAD was synthesized by Genecust and cloned into pBluescript II SK+ digested with PstI and XhoI, generating plasmid pUWM1371. Thereafter, to prepare the $\mathrm{rCjaAD}$ overexpression vector, plasmid pUWM1371 was digested with NheI and XhoI restriction enzymes and a $0.9 \mathrm{~kb}$ DNA fragment was inserted into pET28a, generating plasmid pUWM1379. Correct construction of the recombinant plasmid was verified by sequencing. Protein production was confirmed by Western blot, using previously obtained rabbit polyclonal anti-CjaD and anti-CjaA sera, and anti-6His serum (Pawelec et al., 2000; Łaniewski et al., 2012). RCjaAD has a 6His tag fused to both the $\mathrm{N}$ - and $\mathrm{C}$-termini to allow purification by affinity chromatography.

The construction of the CjaA expression vector ( $\mathrm{PUWM1146)}$ and $\mathrm{CjaD}$ expression vector (pUWM1292) was described previously (Łaniewski et al., 2014; Kobierecka et al., 2015).

\section{Construction of the Shuttle Vector pUWM1000}

The previously described L. lactis plasmid pIL253, based on the pAM $\beta 1$ replicon, does not replicate autonomously in E. coli (Simon and Chopin, 1988). To circumvent this problem, pIL253 was equipped with an ori $p B R$ replicon. A $1.1 \mathrm{~kb}$ XbaI-BglII DNA fragment carrying the $\mathrm{pBR}$ origin of replication was ligated to pIL253 digested with XbaI and BamHI. The resulting shuttle vector pUWM1000 replicates in both E. coli and L. lactis.

\section{Construction of the Vectors Carrying the Fusion of the Campylobacter Genes to the DNA Fragment Encoding the Cell Wall Anchor Region of L. lactis YndF}

The primers UspAx and UspBx were used to amplify the DNA region encoding the signal sequence of Usp45 (amino acids 1-30) from the chromosome of L. lactis IL1403 [PrimeStar HS DNA Polymerase (TaKaRa)]. This region of DNA includes also promoter of the usp45 gene. The UspBx primer contains a $5^{\prime}$ nucleotide sequence complementary to UspCx primer. PCR product that was purified using a Gel-Out extraction kit (A\&A Biotechnology) and the UspCx primer (in equal amounts) was used as a template in a single PCR reaction, using the primers UspAx and UspDx [HiFidelity Polymerase (Qiagen)]. The resulting PCR product was purified and cloned into pGEM-T Easy to generate pUWM1373 (the scheme of pUWM1373 construction is given in Supplementary Figure S1). Construction of this recombinant plasmid via a 2step PCR method allowed the introduction specific restriction enzyme recognition sites, which were useful in cloning procedures.

In order to prepare the translational fusion of $C$. jejuni gene with $3^{\prime}$ end of $L$. lactis $y n d F$ gene, several steps of genetic manipulation were undertaken. First, the nucleotide sequence encoding the C-terminal CWA region of $y n d F$ was PCR amplified from the chromosome of L. lactis IL1403 with primers YndF_XbaI_LPXTG and YndF_ClaI_LPXTG. The $0.4 \mathrm{~kb}$ amplicon was cloned into pGEM-T Easy to generate plasmid pUWM1376. Next, the KpnI-ClaI DNA fragment of pUWM1373, the XbaI-ClaI DNA fragment of pUWM1376 and pBluescript II SK digested with XbaI and KpnI were ligated. The resulting plasmid, designated pUWM1381, contains DNA fragments encoding the signal sequence of the usp45 gene and a DNA fragment encoding the C-terminal CWA region of YndF in the same transcriptional orientation.

Subsequently, pUWM1381 was used to create the translational fusions of $c j a A$ or $r c j a A D$ genes with a signal sequence of usp45 and a nucleotide sequence encoding the C-terminal CWA region of the $y n d F$ gene. Briefly, C. jejuni DNA fragments of $777 \mathrm{bp}$ encoding the cjaA gene that lacks its own signal sequence were PCR-amplified using the primer pair 1001_Bam_LPXTG and 1001_Xho_LPXTG from chromosomal DNA. Next, that fragment was cloned into the pUWM1381 recombinant plasmid using BamHI-XhoI restriction enzymes, to generate the pUWM1384. Construction of a pUWM1382 plasmid containing the translational fusion of the $r c j a A D$ gene with a nucleotide sequence encoding the C-terminal CWA region of YndF was generated by cloning the $0.94 \mathrm{bp}$ XhoI-SphI DNA fragment of pUWM1371 into pUWM1381 linearized with the same restriction enzymes.

Next, the EcoRI-EcoRI fragments containing translational fusions of $c j a A$ or $r c j a A D$ genes with a nucleotide sequence encoding the C-terminal CWA region of YndF were transferred into the pUWM1000 E. coli/L. lactis shuttle vector, generating pUWM1395 and pUWM1392, respectively. Correct construction of the resulting plasmids was confirmed by restriction analysis and sequencing.

\section{Construction of the Vector Encoding Campylobacter Antigens of Cytoplasmic Location}

In-Fusion ${ }^{\circledR}$ HD Cloning technology was employed to generate pUWM1412, the recombinant plasmid containing the rcjaAD gene. The nucleotide sequence encoding the $\operatorname{rcjaAD}$ gene that lacks its own signal sequence was PCR amplified from the pUWM1371 with primers R_CjaAD_inF and F_CjaAD_inF. The primers used added $15 \mathrm{bp}$ nucleotide sequences to each end of the PCR amplicon that are complementary to the two ends of an EcoRI linearized pUWM1000 vector. The cloning procedure was carried out according to the manufacturer's instruction (Clonetech). Correct construction of the resulting plasmid was confirmed by restriction analysis and sequencing.

\section{Transformation of $E$. coli and Lactococcus lactis}

Recombinant plasmids pUWM1392, pUWM1395 and pUWM1412 were introduced into L. lactis IL1403 cells by electroporation as described by Landete et al. (2014). To prepare the competent Lactococcus strains, an overnight culture was 
inoculated 1:50 in GM17 containing 1\% glycine and $0.5 \mathrm{M}$ sucrose and incubated at $30^{\circ} \mathrm{C}$ until an $\mathrm{OD}_{600}$ of 0.6 was reached. Bacteria were collected $\left(10,000 \mathrm{~g}, 10 \mathrm{~min}, 4^{\circ} \mathrm{C}\right)$ and the pellet was washed three times in a washing solution $\left[5 \mathrm{mM} \mathrm{KH}_{2} \mathrm{PO}_{4}, 2 \mathrm{mM}\right.$ $\mathrm{MgCl}_{2}, 10 \%$ glycerol (v/v)] containing $0.5 \mathrm{M}$ sucrose. Bacteria were resuspended 1:100 in the same solution and a volume of $40 \mu \mathrm{L}$ was electroporated immediately or kept at $-70^{\circ} \mathrm{C}$ for further use. L. lactis competent cells were electroporated at $2.5 \mathrm{kV}$, $200 \Omega$ and $25 \mu \mathrm{F}$ in $0.4 \mathrm{~cm}$ cuvettes using a BioRad GenePulser (BioRad, Life Science Research Products, Hercules, CA, USA). After electroporation, Lactococcus cells were resuspended in GM17 broth containing $0.5 \mathrm{M}$ sucrose, $20 \mathrm{mM} \mathrm{MgCl}_{2}$ and $2 \mathrm{mM} \mathrm{CaCl}_{2}$ and incubated at $30^{\circ} \mathrm{C}$ for $2 \mathrm{~h}$. Following the incubation, bacteria were plated on M17 containing $0.5 \mathrm{M}$ sucrose supplemented with erythromycin $\left(5 \mu \mathrm{g} \mathrm{ml}^{-1}\right)$. The plates were incubated at $30^{\circ} \mathrm{C}$ for 2 days.

Escherichia coli was transformed as previously described (Hanahan, 1983).

\section{Recombinant Protein and Polyclonal Antibody Production Overexpression and Purification of CjaA, CjaD and rCjaAD}

rCjaAD was overexpressed and purified from E. coli Rosetta (DE3) pLysS harboring pUWM1379 by autoinduction, as described by Studier (2005). After $24 \mathrm{~h}$ growth, the bacterial culture was centrifuged and the cell pellet was suspended in $50 \mathrm{mM}$ sodium phosphate, $300 \mathrm{mM} \mathrm{NaCl}, 10 \mathrm{mM}$ imidazole, $\mathrm{pH}$ 8.0. Cells were disrupted by sonication. Subsequently, the cell lysate was centrifuged and the resulting supernatant was applied onto a HisTrap column (NGC Chromatography system BioRad). The protein was eluted with an imidazole gradient. Fractions containing $\mathrm{rCjaAD}$ were pooled and extensively dialyzed against phosphate buffered saline (PBS) and used for rabbit immunization. Rabbit immunization was carried out according to the ethical standards and with the approval (5666/2014) of the Local Ethics Committee No. 1, Warsaw, Poland.

The anti-rCjaAD rabbit serum was specific and recognized rCjaAD, as verified by Western blot analysis. Overexpression and all purification steps were monitored by SDS-PAGE. Overexpression and purification of $\mathrm{CjaA}$ and $\mathrm{CjaD}$ were performed using identical method as described previously (Łaniewski et al., 2012; Kobierecka et al., 2015).

\section{SDS-PAGE and Western Blotting}

SDS-PAGE and Western blotting procedures were done by standard techniques. Blots were developed with nitro blue tetrazolium chloride/5-bromo-4-chloro-3-indolyl phosphate (Sigma-Aldrich) as a substrate, using previously obtained rabbit polyclonal anti-CjaA, anti-CjaD (Pawelec et al., 2000; Łaniewski et al., 2012), or anti-rCjaAD (this work) sera or anti-His antibodies (Sigma-Aldrich) as primary antibodies, and mouse anti-rabbit IgG alkaline phosphatase conjugate (Sigma-Aldrich) or goat anti-mouse IgG alkaline phosphatase conjugate as secondary antibodies.

\section{Cellular Localization of the Hybrid Proteins - Immunofluorescence Assay}

For the immunofluorescence assay, L. lactis IL1403 cells carrying plasmids encoding $\mathrm{CjaA}$ or $\mathrm{rCjaAD}$ localized in different areas of the bacteria were used. The immunofluorescence assays were carried out as previously reported (Kobierecka et al., 2015).

Rabbit polyclonal anti-CjaA (Pawelec et al., 2000; Łaniewski et al., 2012) or anti-rCjaAD (this work) sera were used as primary antibodies and goat anti-rabbit IgG Alexa Fluor A488 as secondary antibodies. Fluorescence was visualized with a NIKON A1R MP microscope (University of Warsaw).

\section{Assessment of the Immune Responses and Chicken Protection Growth of Carrier Strain (Lactococcus lactis IL1403 Containing $C$. jejuni rcjaAD or $\operatorname{cja} A$ genes) for Chicken Immunization}

To prepare bacterial suspensions for chicken immunization, an overnight culture of bacteria was diluted 1:50 in fresh prewarmed GM17 broth and grown at $30^{\circ} \mathrm{C}$ to an optical density $\mathrm{A}_{600}=\sim 0.4$. The cells were sedimented by centrifugation at $8000 \times \mathrm{g}$ for $10 \mathrm{~min}$ at $4^{\circ} \mathrm{C}$, and then suspended in buffered saline with $0.1 \%$ gelatin (BSG) to an optical density $\mathrm{A}_{600}=\sim 1$ $\left(\sim 1 \times 10^{9} \mathrm{CFU} / \mathrm{ml}\right)$. CFUs were determined by plating serial dilutions of culture on GM17 agar plates supplemented with $5 \mu \mathrm{g}$ $\mathrm{ml}^{-1}$ erythromycin.

\section{Immunization and Challenge Regimen}

Hy-line chickens were obtained on the day of hatch from a local hatchery. Birds were randomly assigned to experimental groups and housed in an animal facility in separate cages for each group and given water and feed ad libitum. Chickens were confirmed to be culture-negative for Campylobacter by cloacal swabbing. All animal experiments were carried out according to the ethical standards and with the approval (699/2015) of the Local Ethics Committee No. 1, Warsaw, Poland.

Chickens deprived of food and water for $4 \mathrm{~h}$ were orally inoculated with $100 \mu \mathrm{l}$ of $10^{9} \mathrm{CFU} / \mathrm{ml}$ of L. lactis carrying pUWM1392 (SP 1 usp45_rCjaAD_CWA $\left.{ }_{\text {YndF }}\right), \quad$ pUWM1395 $\left(\mathrm{SP}_{\text {usp45_CjaA_CWA }}\right.$ YndF $\left._{1}\right)$ or pUWM1412 (rCjaAD of cytoplasmic location). Booster doses were administrated 8 and 17 days after primary immunization. Following vaccination, chickens were observed for development of diarrhea and other potential adverse side effects. A group of birds inoculated with BSG and L. lactis IL1403 were used as a controls. At the 22nd day of life, birds were orally challenged with $\sim 10^{4}$ CFU of C. jejuni wild-type strain $12 / 2$. At 5 and 9 days post challenge, five birds from each group were euthanized and samples of cecum were collected. Dilutions of the contents were made in PBS and plated onto BA plates supplemented with 5\% horse blood, "Campylobacter Selective Supplement (Blaser-Wang)" and chloramphenicol $\left(15 \mu \mathrm{g} \mathrm{ml}^{-1}\right)$ for enumeration of C. jejuni. Plates were incubated at $37^{\circ} \mathrm{C}$ for $48 \mathrm{~h}$. Plates that were 
culture-negative at $48 \mathrm{~h}$ were reincubated for an additional $48 \mathrm{~h}$. This procedure permits detection of $10^{3} \mathrm{CFU} / \mathrm{g}$ of cecal contents.

To monitor the humoral immune response, three birds from each group were sacrificed on days $7,14,21,27$, and 31 posthatch and samples of serum and gut secretion were collected for the post-mortem examination. On day 1 post hatch, the same number of unvaccinated birds were also euthanized. Blood samples were taken after decapitation. Following centrifugation, sera were collected and stored at $-20^{\circ} \mathrm{C}$. Samples of gut secretions were collected by intestinal lavage. Secretory IgA antibodies were extracted from lower parts of the intestine with PBS containing $0.05 \%$ Tween 20 and soybean trypsin inhibitor $\left(0.1 \mathrm{mg} \mathrm{ml}^{-1}\right)$ (dilution 1:10). Samples were shaken for $2 \mathrm{~h}$ at $4^{\circ} \mathrm{C}$, centrifuged at $20,000 \times g$ for $30 \mathrm{~min}$ at $4^{\circ} \mathrm{C}$, and afterward the supernatant was collected and stored at $-20^{\circ} \mathrm{C}$.

\section{Enzyme-Linked Immunosorbent Assay (ELISA)}

\section{Antigen Preparation}

The 6xHis-tagged rCjaAD protein purified as described above was also used as a coating antigen.

\section{ELISA Assay}

The level of the antibodies against $\mathrm{rCjaAD}$ protein in chicken intestinal secretions and blood sera was quantified by ELISA. Briefly, 96-well Maxisorp plates (Nunc, Rochester, NY, USA) were coated with either the purified $\mathrm{rCjaAD}$ protein $(5 \mu \mathrm{g}$ per well) or Campylobacter membrane proteins (30 $\mu \mathrm{g}$ per well) in PBS and incubated overnight at $4^{\circ} \mathrm{C}$. Then, plates were blocked for $1 \mathrm{~h}$ at $37^{\circ} \mathrm{C}$ with $\mathrm{PBS}$ containing $0.1 \%$ Tween 20 (SigmaAldrich) and 1\% BSA (bovine serum albumin), washed three times with PBS containing 0.1\% Tween 20 (Sigma-Aldrich) and incubated for $1 \mathrm{~h}$ at room temperature with the diluted sera (1:256) or intestinal secretion samples (1:10). Goat antichicken IgA horseradish peroxidase conjugate (Thermo Fisher, Scientific) was employed to detect chicken IgA that bound to Campylobacter antigens. The plates were developed with $3,3^{\prime}, 5,5^{\prime}$-tetramethylbenzidine (Sigma-Aldrich), according to the manufacturer's directions. The reaction was stopped with $3 \mathrm{M}$ $\mathrm{H}_{2} \mathrm{SO}_{4}$ and optical density was determined at $A 490$ using an ELISA reader (Tekan). The level of specific serum IgG was measured using rabbit anti-chicken IgY (whole molecule) alkaline phosphatase conjugate (Sigma-Aldrich). The reaction was run with $p$-nitrophenyl phosphate $\left(1 \mathrm{mg} \mathrm{ml}^{-1}\right)$ as substrate and was stopped after $30 \mathrm{~min}$ incubation (room temperature) with $3 \mathrm{~N}$ sodium hydroxide. Optical density was determined at $405 \mathrm{~nm}$ using an ELISA reader (Tekan). Each sample was analyzed in triplicate.

\section{Bioinformatics Analyses \\ Protein Structure Prediction}

Secondary structure prediction and tertiary fold-recognition (FR) were carried out via the GeneSilico metaserver gateway (Kurowski and Bujnicki, 2003). Solvent accessibility for the individual residues was predicted with SABLE (Adamczak et al., 2005), ACCPRO2 (Cheng et al., 2005a), and JNET (Cuff and Barton, 2000). Disordered residues were predicted from consensus of results generated with disprot (Dunker et al., 2002), DISpro (Cheng et al., 2005b), DisEMBL (Linding et al., 2003), RONN (Yang et al., 2005), and disopred (Ward et al., 2004) methods. Secondary structure was predicted using a consensus of PSIPRED (Jones, 1999b), PROFsec (Rost et al., 2004), PROF (Ouali and King, 2000), SABLE (Adamczak et al., 2005), JNET (Cuff and Barton, 2000), JUFO (Meiler and Baker, 2003), PORTER (Pollastri and McLysaght, 2005), SSPRO2 (Cheng et al., 2005a), and SAM-T02 (Karplus et al., 2003). In all these cases results generated by independent methods were compared and a consensus result was retrieved as a most probable solution. The FR analysis (attempt to match the query sequence to known protein structures) was carried out using PDBBLAST, HHSEARCH (Soding, 2005), FFAS03 (Jaroszewski et al., 2005), FORTE (Tomii and Akiyama, 2004), SAM-T02 (Karplus et al., 2003), 3DPSSM (Kelley et al., 2000), INBGU (Fischer, 2000), FUGUE (Shi et al., 2001), mGENTHREADER (Jones, 1999a), and SPARKS (Zhou and Zhou, 2004). Target-template alignments reported by these methods were compared, evaluated, and ranked by the PCONS server (Lundstrom et al., 2001) to identify the preferred modeling templates and the consensus alignment. The alignments between the amino acid sequences of $\mathrm{CjaA}$ and $\mathrm{CjaD}$ and the structures of the best templates identified by FR were used to carry out homology modeling using Modeler (Sali and Blundell, 1993). For the evaluation of models, a MetaMQAP method was used. (Pawlowski et al., 2008), which allows predicting the deviation of individual amino acid residues in the model from their counterparts in the native structure.

\section{Prediction of Epitopes}

Epitopes were predicted from sequence using the following methods: Chou and Fasman Beta-Turn Prediction (Chou and Fasman, 1978), Emini Surface Accessibility Prediction (Emini et al., 1985), Karplus and Schulz Flexibility Prediction (Karplus and Schulz, 1985), Kolaskar and Tongaonkar Antigenicity (Kolaskar and Tongaonkar, 1990), Parker Hydrophilicity Prediction (Parker et al., 1986), and Bepipred Linear Epitope Prediction (Larsen et al., 2006). All results were compared and consensus predictions were mapped on homology models of $\mathrm{CjaA}$ and $\mathrm{CjaD}$ proteins. We considered consensus fragments that were located in loops exposed to the solvent to be the most probable epitopes.

\section{Statistical Analyses}

Statistical analyses of colonization results were performed using GraphPad Prism 6 (GraphPad Software, Inc., San Diego, CA, USA). The significance of differences between the obtained values was appraised using one-way analysis of variance (ANOVA) followed by the post hoc Tukey test. Statistical analyses of ELISA test were assessed using the Kruskal-Wallis test followed by Dunn's multiple-comparison post hoc test. Statistical analyses were performed using STATISTICA 10PL software (StatSoft, USA). Any $p$-values $<0.05$ were considered significant. 


\section{RESULTS}

\section{Protein Structure Prediction CjaA}

As a starting point for a structural model of CjaA, a protein FR analysis of the CjaA amino acid sequence was performed. FR methods attempt to identify the most appropriate modeling templates for a query sequence and return a set of alternative alignments to proteins of known structure. Most FR methods available in the MetaServer consistently reported the structure of the crystal structure of the cysteinebinding protein from C. jejuni (PDB code: 1xt8) as the potentially best template for modeling the CjaA protein (top matches to 1xt8, with all methods). However, the FR analyses showed no statistically significant similarity to any structurally characterized template for the $\mathrm{N}$ terminal part of CjaA (residues 1-25). A model of the central domain (starting from residue 26) was constructed using the 'FRankenstein's Monster' protocol (Kosinski et al., 2005), and as expected from comparative modeling, the CjaA revealed features of its templates. The prediction of the quality of the final model yields good scores with MQAP methods. The program MetaMQAP predicted that the whole model exhibits a root mean square deviation from the true structure on the order of $5.2 \AA$, and a predicted GDT_TS score of 41.667. These results suggest that our model of CjaA is sufficiently reliable as a framework to interpret sequence-structurefunction relationships in the $\mathrm{CjaA}$, such as analysis of putative epitopes.

\section{CjaD}

As a starting point for a structural model of $\mathrm{CjaD}$, a protein FR analysis of the CjaD amino acid sequence was performed. Most FR methods available in the MetaServer reported two structures: the crystal structure of TolB/Pal complex and the solution structure of peptidoglycan associated lipoprotein from Haemophilus influenzae bound to UDP-Nacetylmuramoyl-L-alanyl-D-glutamyl-meso-2,6-diaminopimel oyl-D-alanyl-D-alanine (PDB codes: 2hqs and 2aiz) as the potentially best templates for modeling of the CjaD protein. However, the residues 1-50 were identified as intrinsically disordered by all methods available in the Metaserver. A model of the central domain (starting from residue 50) was constructed using the 'FRankenstein's Monster' protocol (Kosinski et al., 2005) based on two template structures. The prediction of the quality of the final model yields good scores with MQAP methods. The program MetaMQAP predicted that the whole model exhibits a root mean square deviation from the true structure on the order of $6.7 \AA$, and a predicted GDT_TS score of 34.39. These results suggest that our model of $\mathrm{CjaD}$ is sufficiently reliable as a framework to interpret sequence-structure-function relationships in the $\mathrm{CjaD}$, such as analysis of its putative epitopes.

\section{Prediction of Epitopes}

As a starting point to identify epitopes in CjaA amino acid sequence we performed epitope identification based on

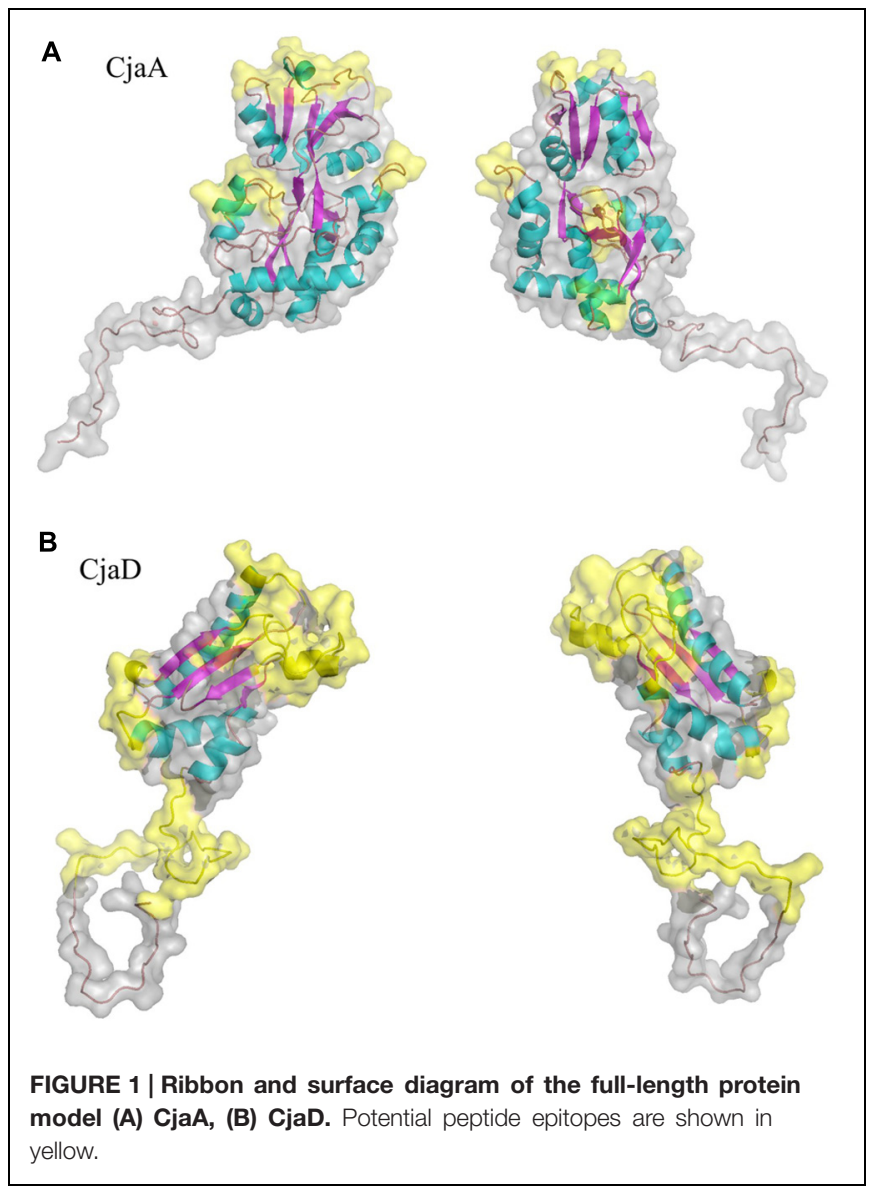

amino acid sequence using five methods (references as in Materials and Methods). Then, we mapped amino acid residues identified by all five methods onto the comparative models of $\mathrm{CjaA}$ and $\mathrm{CjaD}$ built in this work. As putative epitopes, we defined only those from predicted regions of the amino acid sequences that were located on the protein surfaces and visibly exposed to the solvent (Figure 1). The following CjaA fragments were selected as the most probable epitopes: 55-60, 79-82, 111-118, 136-149, 167-171, and 263-268. In the case of $\mathrm{CjaD}$, the $87-91,99-108$, and 139-158 amino acid fragments were indicated as the most probable peptide epitopes.

Additionally, based on the aforementioned predictions, six alternative amino acid sequences of $\mathrm{CjaA}$ with inserted $\mathrm{CjaD}$ epitopes were designed. For this purpose, first we selected five loops in CjaA model that were exposed to the solvent (25-26, 8889, 189-190, 207-208, 218-219) and inserted three CjaD epitopes (EVSGV, DEWGTDEYN, GETNPVCTEKTKACDAQNRR) in all possible combinations (Supplementary Figure S2). Thus, we obtained six alternative amino acid sequences with three $\mathrm{CjaD}$ epitopes each. Finally, we built homology models for all six hybrid amino acid sequences (rCjaAD). The obtained models confirmed that cores of the proteins are unchanged whereas epitopes are inserted into loops exposed to the solvent (Figure 2). 


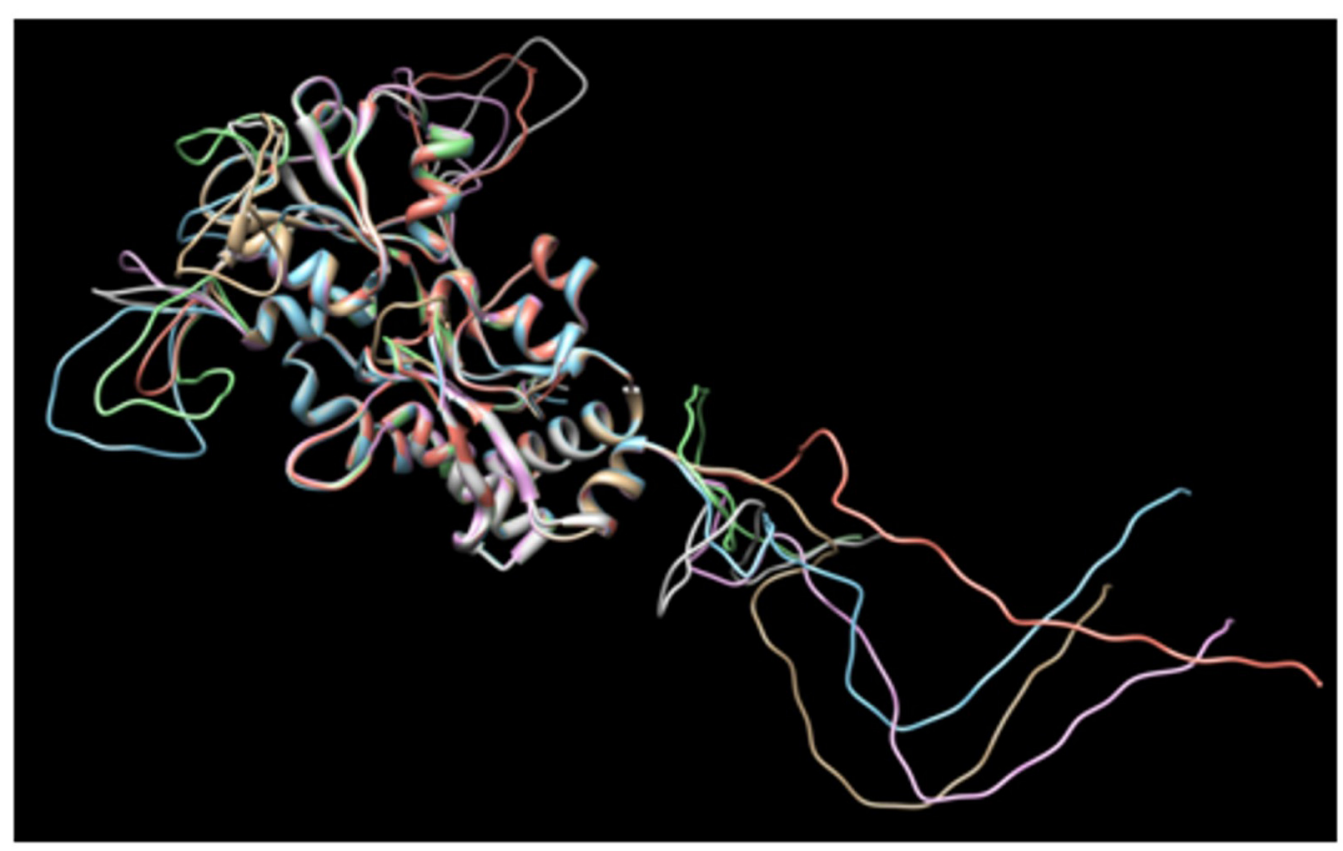

FIGURE 2 | Dimensional structures of each of the proposed amino acid sequences of CjaA with the three insertions of CjaD peptide epitopes.

MKKILLSVLTTFVAVVLAACGGNSDEVSGVSKTLNSLDKIKQNGVVRIGVFGDKPPFGYVDEK GNNQGYDIALAKRIAKELFGDENKVQFVLVDEWGTDEYNEAANRVEFLKSNKVDI ILANFTQT PERAEQVDFCLPYMKVALGVAVPKDSNITSVEDLKDKTLLLNKGTTADAYFTQDYPNIKTLKY DQNTETFAALMDKRGETNPVCTEKTKACDAQNRRGDALSHDNTLLFAWVKDHPDFKMGIKELG NKDVIAPAVKKGDKELKEFI DNLI IKLGQEQFFHKAYDETLKAHF GDDVKADDVVIEGGKI

FIGURE 3 | The amino acid sequence of rCjaAD protein. Amino acids between which peptide epitopes of $\mathrm{CjaD}$ protein (indicated in bold) were inserted are indicated in red.

\section{Construction of CjaA Protein Displaying CjaD Peptide Epitopes on its Surface; Analysis of its Antigenicity and Immunogenicity}

The structure based approach combined with the identification of the $\mathrm{CjaA}$ and $\mathrm{CjaD}$ epitopes allowed us to construct a $\mathrm{CjaA}$ antigen that presents $\mathrm{CjaD}$ epitopes on its surface. Three epitope amino acid sequences (EVSGV, DEWGTDEYN, GETNPVCTEKTKACDAQNRR) from CjaD were inserted at positions 25-26, 88-89, 189-190 of CjaA amino acid sequence (Figure 3). The DNA fragment encoding hybrid protein lacking the CjaA signal sequence ( $\mathrm{rCjaAD}$ ) was synthesized by Genecust and cloned into pBluescript II SK+ (see Materials and Methods). Next, it was recloned into pET28a and introduced into E. coli Rosetta (DE3) pLysS. rCjaAD was overproduced and purified by affinity chromatography.

Next we checked the specificity of $\mathrm{rCjaAD}$ by Western blot experiments. We found that $\mathrm{rCjaAD}$ protein reacts with specific rabbit anti-CjaA, as well as with specific rabbit anti$\mathrm{CjaD}$ sera (Figures $4 \mathrm{~B}, \mathrm{C}$, lane 1 ). As the hybrid protein was constructed with the aim of vaccination, we also investigated its immunogenicity. We found that the specific serum obtained by rabbit immunization with $\mathrm{rCjaAD}$ reacted strongly with both the native $\mathrm{CjaA}$ and the native $\mathrm{CjaD}$ produced by a wild type $C$. jejuni strain (Figure 4A, lane 4).

\section{Construction of the $L$. lactis Strains Expressing C. jejuni Genes}

We constructed two plasmids expressing a fusion of the C. jejuni CjaA or rCjaAD with the cell wall anchor region of YndF (CWAYndF): LPETGDKEQGMKKITLFGSFLLILGSLVLFIRFRKVD). YndF (NP_267457) is a substrate for sortase SrtA. Two mucinbinding domains were identified in this protein, which suggests its possible function in adhesion to epithelial cells or possibly other cells (Dieye et al., 2010).

All genetic manipulations were performed in E. coli. To begin, we constructed a shuttle vector pUWM1000 able to replicate in E. coli and L. lactis strains. The shuttle vector is a derivative of a patented L. lactis plasmid carrying erythromycin resistance (pIL253), in which the ori pBR was introduced in order to ensure its replication in $E$. coli cells. The plasmid was introduced into E. coli by chemotransformation and L. lactis by electroporation.

Next, specific recombinant plasmids to generate fusions of C. jejuni and L. lactis genes were created. First, the promoter and DNA fragment coding for a signal peptide (SP) of Usp45 L. lactis protein (a $45 \mathrm{kDa}$ secreted protein of unknown function) was introduced into pGEM-Easy to allow secretion of produced antigens. At the same time, the PCR-amplified DNA fragment encoding the CWA region of YndF was inserted into pGEMT Easy. The resulting plasmids (pUWM1373 and pUWM1376, respectively) were the source of fragments, which were connected in the same transcriptional orientation in pBluescript II SK 


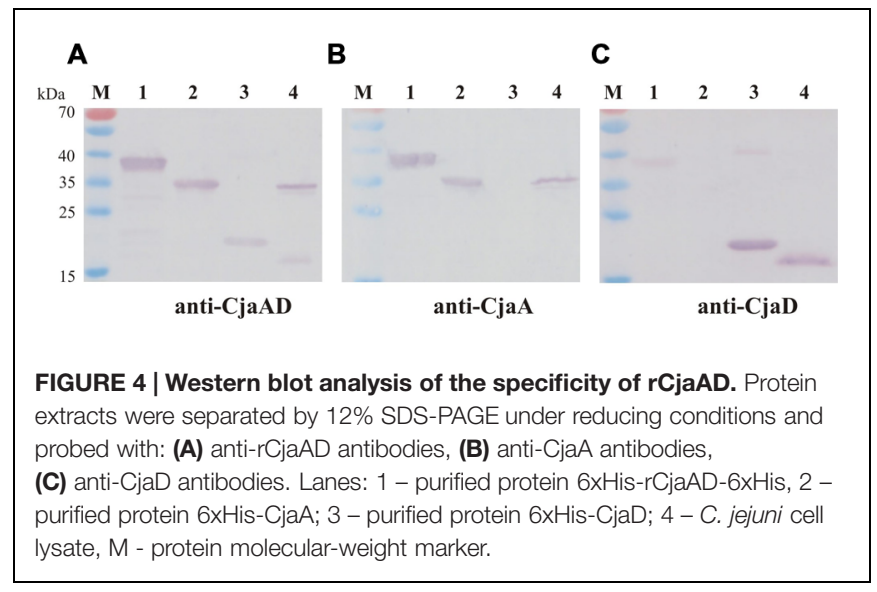

in the next step (pUWM1381). There are different nucleotide sequences recognized by restriction enzymes located at the junction between the $3^{\prime}$ end of the DNA region encoding the $\mathrm{SP}_{\mathrm{Usp} 45}$ signal sequence and the $5^{\prime}$ end of L. lactis DNA encoding the CWA region of YndF. This strategy facilitates cloning of $C$. jejuni genes. The last stage of the construction work included the insertion of two C. jejuni genes (encoding $\mathrm{CjaA}$ and $\mathrm{rCjaAD}$, respectively) in such a way that both are expressed from the Usp45 promoter. The proteins lack the CjaA signal sequence but are equipped with the Usp45 signal sequence and are fused to the C-terminus of YndF. The details of construction are shown in Figure 5 and Supplementary Figure S3.

Finally, the DNA fragments of pUWM1384 or pUWM1382 encoding CjaA or rCjaAD fused to C-terminus of YndF were transferred into the pUWM1000 shuttle vector to generate pUWM1395 and pUWM1392, respectively. The correctness of constructed recombinant plasmids was verified by sequencing at every step of work. pUWM1392 and pUWM1395 were introduced into $L$. lactis by electrotransformation. Next, we confirmed the production of $\mathrm{CjaA}$ and $\mathrm{rCjaAD}$ by L. lactis by Western blotting experiments. We found that L. lactis contained plasmids harboring the $r c j a A D$ or $c j a A$ genes expressed proteins with approximate molecular masses of $\sim 53$ or $\sim 50 \mathrm{kDa}$, respectively. Molecular masses of the proteins reacting with specific rabbit sera against $\mathrm{CjaA}$ or $\mathrm{rCjaAD}$ were consistent with the calculated sizes of the $\mathrm{CjaA}$ or $\mathrm{rCjaAD}$ fusions with CWA region of YndF (Supplementary Figure S4, lines 1 and 2).

To confirm the impact of the C-terminus of YndF on protein location and subsequently on the efficacy of vaccination, we also constructed two $L$. lactis strains harboring the recombinant plasmid that encodes Campylobacter rCjaAD antigen with a cytoplasmic localization (pUWM1492). Details of its construction are described in the methods section. The protein produced by this strain, which reacts with anti-rCjaAD serum, has the expected molecular mass (Supplementary Figure S4, line 3).

\section{Localization of $\mathrm{CjaA}$ and $\mathrm{rCjaAD}$ Proteins}

We next investigated the localization of $\mathrm{CjaA}$ and $\mathrm{rCjaAD}$ by immunofluorescence assay. We found that the L. lactis IL1403 strain bearing the fusion $\mathrm{SP}_{\mathrm{Usp} 45 \_}$rCjaAD_CWA ${ }_{\text {YndF }}$ displayed strong fluorescence. Fluorescence was also observed for $\mathrm{SP}_{\mathrm{Usp} 45}$ C CjaA_CWA $\mathrm{AndF}_{\mathrm{Y}}$ protein, though not as intense as the $\mathrm{SP}_{\mathrm{Usp} 45}$ rCjaAD_CWA $\mathrm{YndF}_{\mathrm{Y}}$ protein. In contrast, no fluorescence was observed in cells of L. lactis strain harboring a recombinant plasmid encoding Campylobacter rCjaAD antigen with a cytoplasmic location. The results are given in Figure 6.

\section{Chicken Immunization with $L$. lactis Producing Surface Exposed Hybrid Protein rCjaAD}

Many Lactic Acid Bacteria (LAB) have received Generally Regarded as Safe (GRAS) status, and some of them are recognized as probiotics (Fontana et al., 2013; Wyszyńska et al., 2015). This makes LAB strains such as L. lactis suitable as potential vectors for chicken vaccination against Campylobacter. Our constructed L. lactis strain, expressing surface exposed $\mathrm{rCjaAD}$, was used for chicken immunization
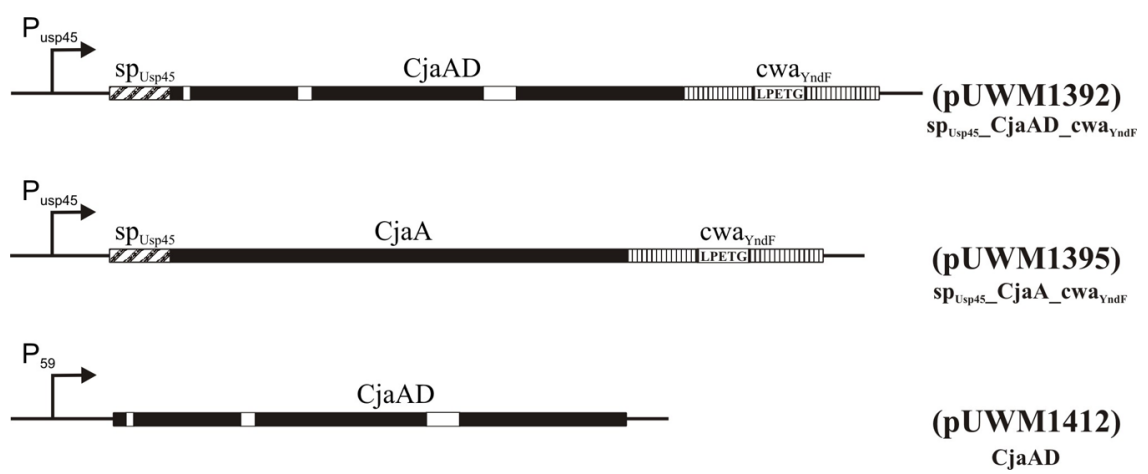

FIGURE 5 | Schematic representation of the hybrid proteins. $\mathrm{P}_{59}$ and $\mathrm{P}_{\text {Usp45 }}$ are strong, constitutive lactococcal promoters (van der Vossen et al., 1987), sp refers to the signal peptide of Usp45 (van Asseldonk et al., 1990) and cwa to the cell wall anchor region of the lactococcal protein YndF. Epitopes of CjaD proteins are marked with white rectangles. The corresponding plasmids are indicated in parentheses. 
A
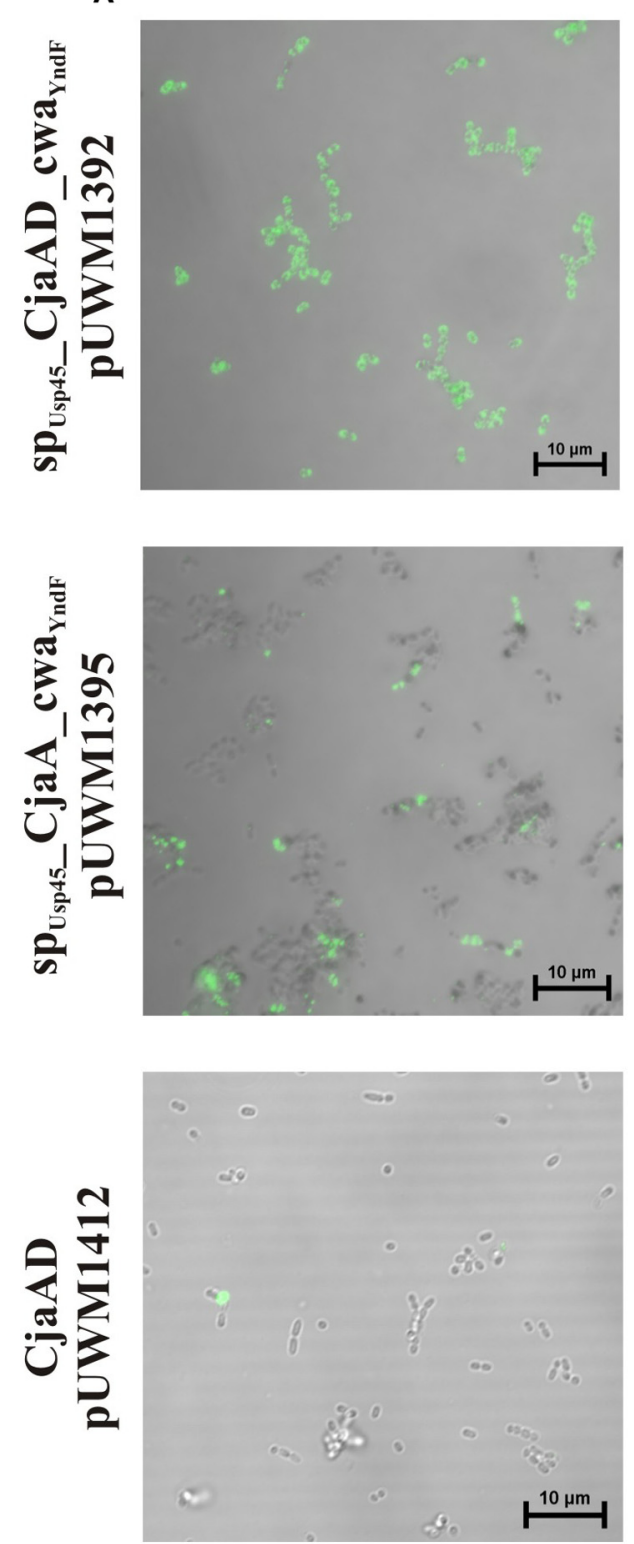

B
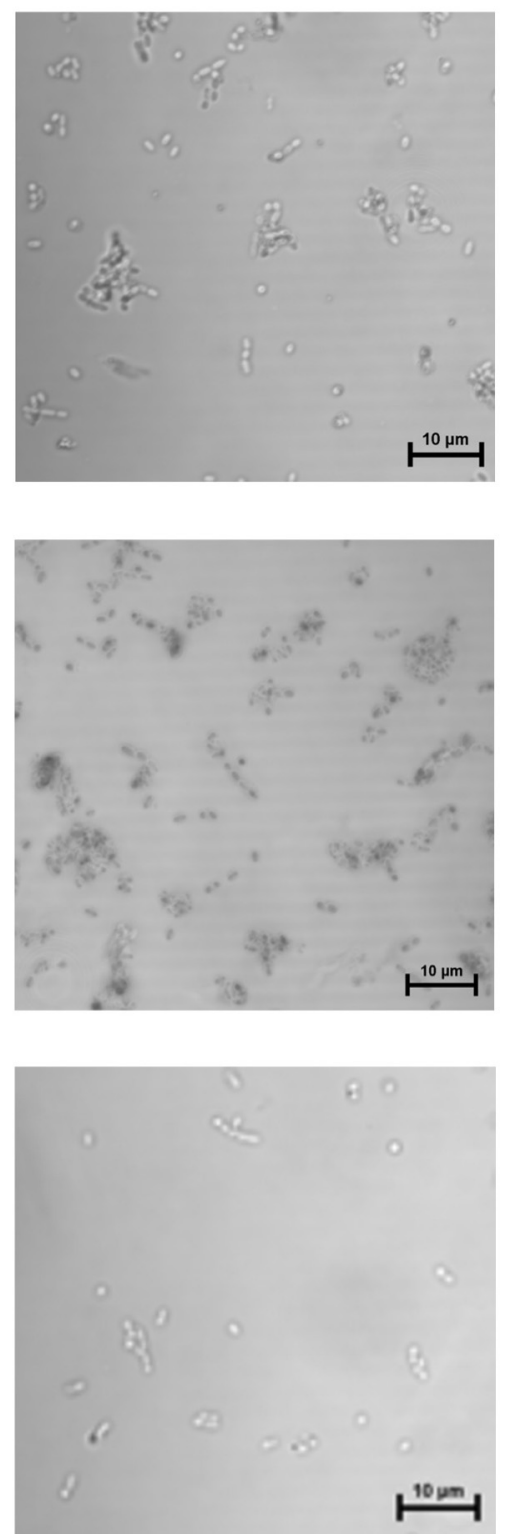

FIGURE 6 | Localization of SP Usp45_rCjaAD_CWAYndF, SP Usp45_CjaA_CWAYndF and CjaA proteins on L. lactis IL1403 cells. Microscopic observations of the $L$. lactis strains expressing the fusion genes: spusp45_rcjaAD_cwaYndF, spusp45_cjaA_cwayndF and rcjaAD. (A) Shows bacterial cells whose fusion proteins were visualized with anti-CjaA or anti-rCjaAD antibodies that were further detected with goat anti-rabbit IgG Alexa Fluor A488. (B) Primary antibodies were omitted (negative controls). Fluorescence was visualized with a NIKON A1R MP microscope. The bar represents $10 \mu \mathrm{m}$.

in order to evaluate how well it provided protection against Campylobacter infection and to assess the induced immune responses. Additionally, to assess the role of protein localization and to evaluate the impact of a hybrid protein containing epitopes derived from two immunogenic proteins, two additional L. lactis strains were included in the experiment. One (L. lactis /pUWM1412) produces cytoplasm-localized rCjaAD, and the second produces surface-localized CjaA (L. lactis /pUWM1395). The scheme of the experiments is depicted in Table 3.
Briefly, three groups of 1-day old chickens (19 per each group) were orally immunized with $L$. lactis strains expressing C. jejuni antigens (details are given in Materials and Methods). Chickens were boosted with the same doses of the same strains at 8 and 17 days post-hatch. Two groups of birds, one inoculated with BSG and the second inoculated with L. lactis IL1403 were used as a controls. The rationale behind this schedule of immunization is the fact that the immune system of chickens remains immature for the first 2 weeks of life (Mast and Goddeeris, 1999; Bar-Shira et al., 2003). Additionally, maternal antibodies, mainly directed 
TABLE 3 | Scheme of immune response and protection experiments.

\begin{tabular}{|c|c|c|c|c|c|c|c|c|c|}
\hline Day of life & 1 & 7 & 8 & 14 & 17 & 21 & 22 & 27 & 31 \\
\hline Immunization with Lactococcus & + & & + & & + & & & & \\
\hline Collection of blood and gut secretion samples for immune response analyses & + & + & & + & & + & & + & + \\
\hline Challenge with Campylobacter & & & & & & & + & & \\
\hline Cecum isolation for Campylobacter enumeration & & & & & & & & + & + \\
\hline
\end{tabular}

Note: + indicates when the procedures occurred.

against outer-membrane proteins, may restrict the induction of an immune response.

\section{Serum and Intestinal Antibody Responses}

To investigate the immunogenicity of the surface-exposed rCjaAD hybrid protein delivered by L. lactis, serum IgYs and mucosal IgAs were measured by ELISA using $\mathrm{rCjaAD}$ as coating antigen. The kinetics of the induction of two kinds of antibodies (specific IgYs and specific IgAs) varies significantly (Figures 7A,B). Systemic IgY responses to Campylobacter antigens were observed at days 7 and 14 (after the first and the second dose of vaccine), decreased at days 21 and 27, and finally increased at day 31 when the experiment was terminated (Figure 7A). The high level of specific IgYs observed during the first 2 weeks of chicken life represents maternal antibodies. The vaccinated groups (with one exception) had higher levels of specific IgYs on days 7 and 14 than the group vaccinated with carrier strain. These results indicate that vaccination may support the protective activity of maternal antibodies. The extremely high level of specific IgG induced by L. lactis/pUWM1392 (surface exposed rCjaAD) and low level induced by L. lactis/pUWM1395 (surface exposed CjaA) observed at day 14 is not clear. The antirCjaAD IgY response at day 31 elicited by L. lactis harboring Campylobacter antigens is significantly higher than the control group. The highest titer of the anti-rCjaAD antibodies was detected after immunization with the L. lactis that presented hybrid protein on its surface. Generally, mucosal IgAs are regarded as the first line of immune defense against many pathogens. Anti-rCjaAD mucosal IgA titers increased in all immunized group after the second booster (day 21). In the case of specific anti-rCjaAD mucosal IgAs, no correlation was noticed between the level of the induced immune response and antigen localization. Anti-rCjaAD IgA responses in the three groups immunized with L. lactis strains were similar, both in kinetics and titer at all points of the experiment (Figure 7B).

\section{Protection Analysis}

To determine whether the $\mathrm{rCjaAD}$ delivered by L. lactis provides protection against Campylobacter infection, immunized chickens were challenged orally with $8 \times 10^{4}$ bacterial cells of a broilerisolated $C$. jejuni strain 5 days after the second booster. The C. jejuni strain used for the challenge experiment was labeled with the pUOA18 plasmid containing a cat gene. Protection was assessed at 5 and 9 days after the challenge by plating to determine the level of bird's caeca colonization by wild type Campylobacter.
There was a noticeable, though not statistically significant, reduction in the CFUs (colony forming units) of $C$. jejuni in the cecal contents of birds immunized with L. lactis that produced surface-exposed rCjaAD (pUWM1392), as compared to control group (Figure 8). The mean CFU/gram of cecal content observed in this group was about $1 \times 10^{7}$ whereas the mean level of colonization in the control group was $1 \times 10^{8} \mathrm{CFU} /$ gram. In the control group receiving $L$. lactis vector strain, no reduction in the colonization level was noticed, as compared to group receiving BSG, especially 9 days after the challenge. It should be noted that among three vaccinated groups, the group immunized with $L$. lactis producing surface-located $\mathrm{rCjaAD}$ displayed the lowest range in the level of colonization. Additionally in this group, the immunization of two out of six birds resulted in reduction of cecal $C$. jejuni by about $2 \log _{10}$ units compared to birds receiving BSG at 9 days after challenge. Based on the mean level of colonization, vaccination with L. lactis/pUWM1395 (surface-exposed CjaA) does not result in protection against C. jejuni colonization. However, in this case the highest range of colonization levels was observed between individual chickens. While vaccination with $L$. lactis/pUWM1392 producing surfacelocated $\mathrm{rCjaAD}$ resulted in reduction of $C$. jejuni colonization at 5 and 9 days post-challenge, the reduction observed after immunization with an L. lactis strain producing the same antigen, but cytoplasmically located, is noted only for a short time. At day 9 post-challenge, the mean level of colonization was even slightly higher compared to the non-vaccination group. However, this group also had significant differences in the level of colonization between individual birds.

\section{DISCUSSION}

Campylobacter sp. infection remains the leading cause of human food-borne gastroenteritis in industrialized countries. The occurrence of high loads of Campylobacter cells in the chicken digestive tract is still prevalent in broiler flocks (EFSA and ECDC, 2015). So there is an urgent need to control chicken contamination by Campylobacter. Many interventions aimed at lowering the level of chicken-carcass contamination during the poultry production cycle have recently been proposed and tested. However, the currently available interventions are of limited effectiveness or difficult to sustain (Hermans et al., 2011b; Josefsen et al., 2015). Thus, the market needs an effective antiCampylobacter chicken vaccine. Recent progress has been made to understand the complex Campylobacter biology during chick colonization, as well as improvements in the technologies used 


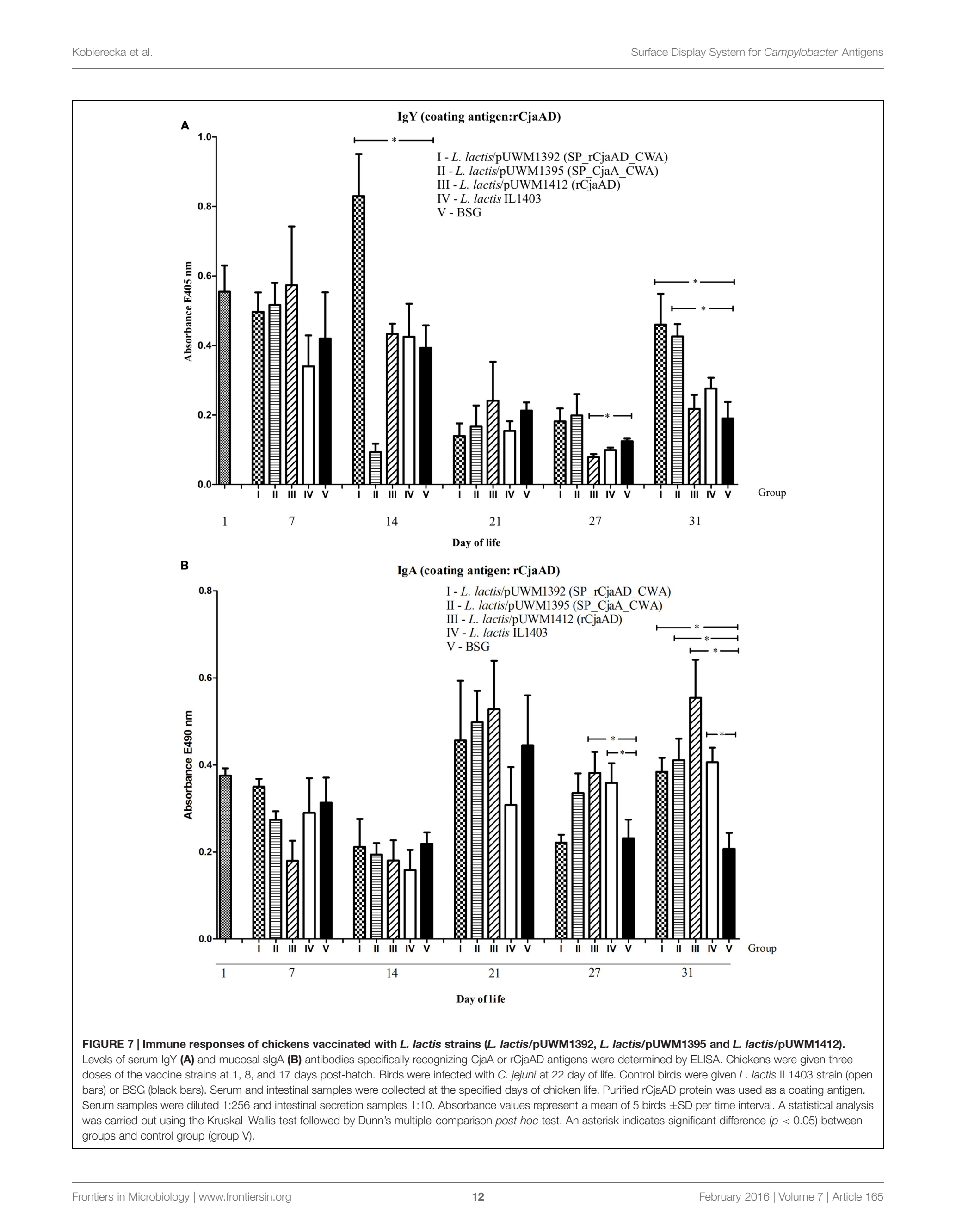




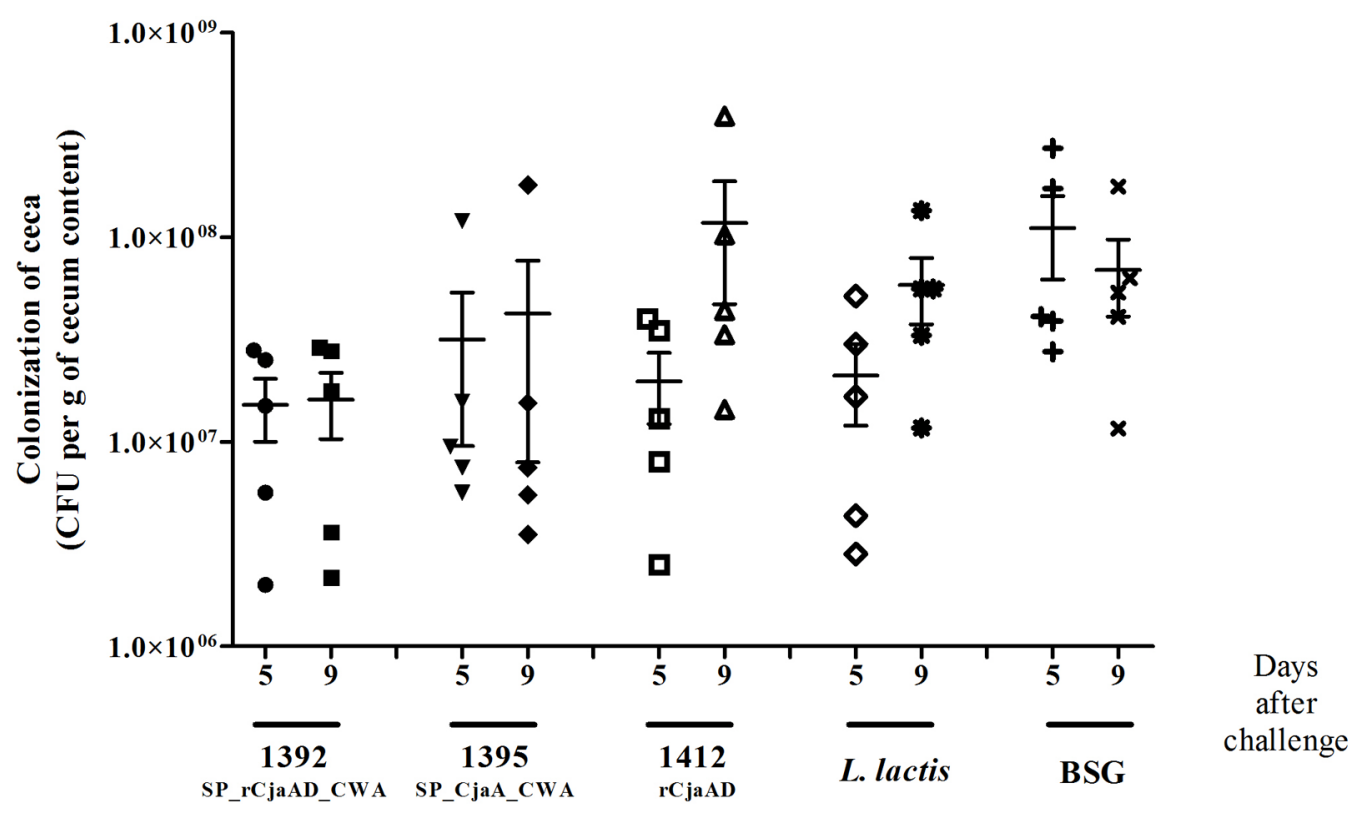

FIGURE 8 | Colonization of chickens vaccinated with L. lactis strains (L. lactis/pUWM1392, L. lactis/pUWM1395 and L. lactis/pUWM1412) and then given a $\mathbf{C}$. jejuni challenge. Chickens were given three doses of the vaccine strains at 1,8 , and 17 days after hatch and challenged with $C$. jejuni $12 / 2 / p U O A 13$ 5 days later. Control birds were given BSG. Viable $C$. jejuni cells were recovered from the ceca of chickens at specified days after challenge. Bacterial recoveries represent colonization levels of 5 birds per time interval. The geometric mean for each group is denoted by bars. No significant differences $(p<0.05)$ between groups were seen.

for identifying the immunodominant proteins (Hermans et al., 2011a; Hoppe et al., 2014; Hu et al., 2014); both of these facilitate the selection of antigens for immunization.

Based on the results of chicken vaccination experiments presented by us and others (Wyszyńska et al., 2004; Buckley et al., 2010; Layton et al., 2011), and also on known facts about Campylobacter physiology and genomics, we decided to use two conserved, extracytoplasmic and highly immunogenic proteins, CjaA and CjaD (Konkel et al., 1996; Pawelec et al., 1997; Pawelec et al., 2000), for the experiments in this paper. CjaA is a periplasmic, cysteine binding protein (Muller et al., 2005), and $\mathrm{CjaD}$ is a peptidoglycan-associated essential protein (PAL) responsible for the integrity of bacterial cell wall (Godlewska et al., 2009). Additionally, CjaA was found among the proteins recognized by maternal antibodies that protect young chicks against Campylobacter infection (Shoaf-Sweeney et al., 2008). Analysis of the genomes of members of the Campylobacter genus, species other than C. jejuni, indicate CjaA as a core-virulence factor and potential candidate for subunit vaccine development (Ali et al., 2012). Given that several Campylobacter species have recently been recognized as emerging animal or human pathogens, this particular characteristic of CjaA is significant (Kaakoush et al., 2015). To facilitate antigen production by the vector strain and to overcome, at least partially, the problem created by the various Campylobacter genotypes, we constructed a hybrid protein: a CjaA that presents $\mathrm{CjaD}$ epitopes on its surface. Detailed bioinformatics analysis allowed us to determine the $\mathrm{CjaD}$ epitopes and specify the appropriate places to introduce them into the $\mathrm{CjaA}$ amino acid sequence. Structural modeling verified the construction of the hybrid protein. It showed that the CjaA structure was not disturbed and that the selected $\mathrm{CjaD}$ epitopes were present on the CjaA surface. The immunogenicity of $\mathrm{rCjaAD}$ was documented by rabbit immunization; the rabbit serum obtained after immunization with $\mathrm{rCjaAD}$ reacted with $\mathrm{CjaA}$ or $\mathrm{CjaD}$ present in a wild type Campylobacter strain. A similar approach has recently been presented by Konkel et al. (1996) who showed that intramuscular immunization with a subunit vaccine that consists of epitopes from three surface-exposed colonization proteins (CadF-FlaA-FlpA), combined with adjuvant, gave a significant reduction of Campylobacter colonization (Neal-McKinney et al., 2014). However, due to the biology of Campylobacter infection it is generally considered that oral antigen administration will be the most effective way to immunize chickens. As shown by Theoret et al. (2012) the mode of antigen delivery is sometimes crucial for immunization. They noticed that subcutaneous vaccination with purified rDps (DNA binding protein from starved cells) did not reduce colonization of chickens by Campylobacter, whereas the same protein delivered by an attenuated Salmonella appeared to be effective (Theoret et al., 2012). The importance of humoral immune response in preventing chicken colonization by Campylobacter has been recently documented by Hermans et al. (2014). They showed that passive immunization of 6 days old chicks with IgY obtained from egg yolks of hens immunized with C. jejuni lysates or fraction of $C$. jejuni hydrophobic proteins resulted not only in reduction their colonization by homologous $C$. jejuni strain but also reduce the pathogen transmission to not infected 
birds (Hermans et al., 2014). More and more LAB, mainly members of the Lactococcus and Lactobacillus genera, have been tested as vehicles for the delivery of heterologous bacterial or viral antigens into animal mucosal immune systems (Marelli et al., 2011; Villena et al., 2011; Kajikawa et al., 2012; Fontana et al., 2013; Li et al., 2014). In this work, we employed L. lactis because genetic engineering tools for this bacterium have been worked out in detail (Fontana et al., 2013). To the best of our knowledge, our work is the first attempt to use an LAB strain as a Campylobacter antigen delivery vehicle for chicken immunization. Although we observed a positive result from immunization, the reduction of chicken digestive tract colonization by Campylobacter after vaccination was not significant and was lower than that described previously by us and others (Wyszyńska et al., 2004; Layton et al., 2011). The median reduction in C. jejuni cecal contents observed after vaccination with surface-exposed hybrid protein was $1 \log _{10}$ However, it should be noted than there was about a $2 \log _{10}$ reduction in the level of colonization for four out of 10 birds. The main drawback of the L. lactis delivery vehicle is the lack of long-lasting colonization in the chick digestive tract. Thus, we postulate that it may be necessary to optimize the number of vaccine doses to improve the effectiveness of vaccination. Alternatively, using Lactobacillus sp. that colonize bird intestines should result in more efficient induction of the immune response (Wyszyńska et al., 2015).

The significant differences among published results of chicken vaccination against Campylobacter are apparent. The reduction in chicken colonization observed in protection experiments varies between $6 \log _{10}$ to $1 \log _{10}$ when compared to control groups (Wyszyńska et al., 2004; Buckley et al., 2010; Layton et al., 2011; Theoret et al., 2012). However, those various experiments differ substantially. Comparison of the experiments is difficult, if not impossible, because of differences in the nature of the antigens, the routes of antigen administration, the use of adjuvant, and the schemes of immunization or challenge experiments. Additionally, recent progress in chicken genome sequencing has revealed enormous differences among commercial breeds of broiler chickens (Rubin et al., 2010; Yan et al., 2014; Yi et al., 2014). These differences may have an impact on the bird immune system functioning and on colonization by Campylobacter (Humphrey et al., 2014). Differences in the immune responses to infection were observed not only among various breeds of chickens but also between among individual birds of the same population (Connell et al., 2012), which may explain the varying levels of colonization observed between individual birds in our protection experiments (see Figure 8). Also, the gastrointestinal microbiome of chickens differs for genetically diverse birds (Oakley et al., 2014; Schokker et al., 2015). Thus, in the light of the knowledge from the global analysis of chicken genomes or transcriptomes, it is apparent that the chicken line is of great importance when vaccine prototypes are evaluated. Also, the presence of maternal antibodies should be taken into account when results of immunization are evaluated. To exclude the impact of maternal antibodies, some experiments have been conducted on SPF chickens (Buckley et al., 2010; Hodgins et al., 2015).

Many recent experiments have sought to clarify how the location of antigen delivered by LAB strains affects the efficacy of vaccination (Reveneau et al., 2002; Wyszyńska et al., 2015). Generally, surface located antigens work more efficiently than those located in the cytoplasm; however, some exceptions were also observed (Shaw et al., 2000). Thus, this issue needs to be evaluated individually for each antigen and delivery vector. Our protection experiments demonstrated that the hybrid protein, equipped with a cellwall anchored motif and delivered orally using L. lactis as a vehicle, acted more effectively than cytoplasm-located protein administered by the same strain. Also, using the hybrid $\mathrm{rCjAD}$ protein resulted in a higher level of protection when compared to surface-located CjaA. It should be noted that one of the $\mathrm{CjaD}$ epitopes inserted into $\mathrm{CjaA}$ was the same as that used by Layton et al. (2011). However, Layton et al. (2011) demonstrated a much higher level of protection. The reasons for the discrepancy are difficult to identify as both vaccination experiments differ substantially. One notable difference is that the Salmonella strain used by the Layton group as the carrier strain co-expressed the immune-enhancing region of the CD154 ligand (Layton et al., 2011).

Overall, our work demonstrates the possibility of delivering foreign antigens via an $\mathrm{LAB}$ vector for chicken immunization against Campylobacter, and it also documents that CjaA is a good starting point for constructing a multi-epitope hybrid protein taking into account recently identified immunogenic C. jejuni proteins present in egg yolks of immunized hens (Hermans et al., 2014). Hybrid proteins containing epitopes of several immunogenic proteins may ensure higher levels of protection than vaccination with individual proteins.

\section{AUTHOR CONTRIBUTIONS}

EJ-K, AW, and PK conceived and designed the study. PK, $\mathrm{AW}, \mathrm{BO}, \mathrm{MK}$, and $\mathrm{KD}$ carried out the laboratory work. AW, PK, PM, IA carried out animal experiment. EJ-K, $\mathrm{PK}$, and AW analyzed the data. EJ-K, AW, and PK wrote the manuscript. All authors read and approved the final manuscript.

\section{FUNDING}

The work was supported by grants from the National Science Center, Poland (grants No 2011/03/B/NZ1/00592).

\section{ACKNOWLEDGMENTS}

We thank Dr. J. Hansen for his critical reading of the manuscript. Bioinformatic analyses were performed by VitaInSilica Sp. z o. o., Zlotniki, Poland. 


\section{SUPPLEMENTARY MATERIAL}

The Supplementary Material for this article can be found online at: http://journal.frontiersin.org/article/10.3389/fmicb. 2016.00165

FIGURE S1 | The scheme of pUWM1373 construction.

FIGURE S2 | Amino acid sequence of CjaA containing inserted three CjaD peptide epitopes (EVSGV, DEWGTDEYN, GETNPVCTEKTKACDAQNRR) in

\section{REFERENCES}

Adamczak, R., Porollo, A., and Meller, J. (2005). Combining prediction of secondary structure and solvent accessibility in proteins. Proteins 59, 467-475. doi: $10.1002 /$ prot.20441

Ali, A., Soares, S. C., Santos, A. R., Guimaraes, L. C., Barbosa, E., Almeida, S. S., et al. (2012). Campylobacter fetus subspecies: comparative genomics and prediction of potential virulence targets. Gene 508, 145-156. doi: 10.1016/j.gene.2012.07.070

Bar-Shira, E., Sklan, D., and Friedman, A. (2003). Establishment of immune competence in the avian GALT during the immediate post-hatch period. Dev. Comp. Immunol. 27, 147-157. doi: 10.1016/S0145-305X(02) 00076-9

Buckley, A. M., Wang, J., Hudson, D. L., Grant, A. J., Jones, M. A., Maskell, D. J., et al. (2010). Evaluation of live-attenuated Salmonella vaccines expressing Campylobacter antigens for control of C. jejuni in poultry. Vaccine 28, 1094 1105. doi: 10.1016/j.vaccine.2009.10.018

Cawthraw, S. A., and Newell, D. G. (2010). Investigation of the presence and protective effects of maternal antibodies against Campylobacter jejuni in chickens. Avian Dis. 54, 86-93. doi: 10.1637/9004-072709-Reg.1

Chaloner, G., Wigley, P., Humphrey, S., Kemmett, K., Lacharme-Lora, L., Humphrey, T., et al. (2014). Dynamics of dual infection with Campylobacter jejuni strains in chickens reveals distinct strain-to-strain variation in infection ecology. Appl. Environ. Microbiol. 80, 6366-6372. doi: 10.1128/AEM.01901-14

Cheng, J., Randall, A. Z., Sweredoski, M. J., and Baldi, P. (2005a). SCRATCH: a protein structure and structural feature prediction server. Nucleic Acids Res. 33, W72-W76. doi: 10.1093/nar/gki396

Cheng, J., Sweredoski, M., and Baldi, P. (2005b). Accurate prediction of protein disordered regions by mining protein structure data. Data Min. Knowl. Discov. 11, 213-222. doi: 10.1016/j.phrp.2014.06.006

Chopin, A., Chopin, M. C., Moillo-Batt, A., and Langella, P. (1984). Two plasmiddetermined restriction and modification systems in Streptococcus lactis. Plasmid 11, 260-263. doi: 10.1016/0147-619X(84)90033-7

Chou, P. Y., and Fasman, G. D. (1978). Prediction of the secondary structure of proteins from their amino acid sequence. Adv. Enzymol. Relat. Areas Mol. Biol. 47, 45-148.

Clark, J. D., Oakes, R. D., Redhead, K., Crouch, C. F., Francis, M. J., Tomley, F. M., et al. (2012). Eimeria species parasites as novel vaccine delivery vectors: anti-Campylobacter jejuni protective immunity induced by Eimeria tenella-delivered CjaA. Vaccine 30, 2683-2688. doi: 10.1016/j.vaccine.2012. 02.002

Connell, S., Meade, K. G., Allan, B., Lloyd, A. T., Kenny, E., Cormican, P., et al. (2012). Avian resistance to Campylobacter jejuni colonization is associated with an intestinal immunogene expression signature identified by mRNA sequencing. PLoS ONE 7:e40409. doi: 10.1371/journal.pone.0040409

Cuff, J. A., and Barton, G. J. (2000). Application of multiple sequence alignment profiles to improve protein secondary structure prediction. Proteins 40, 502511. doi: 10.1002/1097-0134(20000815)40:3<502::AID-PROT170>3.0.CO;2-Q

de Zoete, M. R., van Putten, J. P., and Wagenaar, J. A. (2007). Vaccination of chickens against Campylobacter. Vaccine 25, 5548-5557. doi: 10.1016/j.vaccine.2006.12.002

Delany, I., Rappuoli, R., and De Gregorio, E. (2014). Vaccines for the 21st century. EMBO Mol. Med. 6, 708-720. doi: 10.1002/emmm.201403876

Dieye, Y., Oxaran, V., Ledue-Clier, F., Alkhalaf, W., Buist, G., Juillard, V., et al. (2010). Functionality of sortase A in Lactococcus lactis. Appl. Environ. Microbiol. 76, 7332-7337. doi: 10.1128/AEM.00928-10 all possible combinations. Amino acids between which epitopes of CjaD protein were inserted are indicated in red.

\section{FIGURE S3 | The scheme of pUWM1392 and pUWM1395} construction.

FIGURE S4 | The production of CjaA and rCjaAD by L. lactis. Protein extracts were separated by $12 \%$ SDS-PAGE under reducing conditions and probed with anti-rCjaAD antibodies. Lanes: $M$ - protein molecular-weight marker, 1 - L. lactis/pUWM1392, 2 - L. lactis/pUWM1395;

$3-$ L. lactis/pUWM1412.

Dunker, A. K., Brown, C. J., Lawson, J. D., Iakoucheva, L. M., and Obradovic, Z. (2002). Intrinsic disorder and protein function. Biochemistry 41, 6573-6582. doi: $10.1021 / \mathrm{bi} 012159$

EFSA and ECDC (2015). The european union summary report on trends, and sources. (of) zoonoses, zoonotic agents and foodborne outbreaks in 2013. EFSA J. 13:3991. doi: 10.2903/j.efsa.2015.3991

EFSA Panel on Biological Hazards (BIOHAZ) (2011). Scientific opinion on Campylobacter in broiler meat production: control options, and performance objectives, and/or targets. (at )different stages of the food chain. EFSA J. 9:2105. doi: 10.2903/j.efsa.-2011.2105

Emini, E. A., Hughes, J. V., Perlow, D. S., and Boger, J. (1985). Induction of hepatitis A virus-neutralizing antibody by a virus-specific synthetic peptide. J. Virol. 55, 836-839.

Fischer, D. (2000). Hybrid fold recognition: combining sequence derived properties with evolutionary information. Pac. Symp. Biocomput. 5, 119-130. doi: 10.1142/9789814447331_0012

Fontana, L., Bermudez-Brito, M., Plaza-Diaz, J., Munoz-Quezada, S., and Gil, A. (2013). Sources, isolation, characterisation and evaluation of probiotics. Br. J. Nutr. 109(Suppl. 2), S35-S50. doi: 10.1017/S0007114512004011

Friis, C., Wassenaar, T. M., Javed, M. A., Snipen, L., Lagesen, K., Hallin, P. F., et al. (2010). Genomic characterization of Campylobacter jejuni strain M1. PLoS ONE 5:e12253. doi: 10.1371/journal.pone.0012253

Gilbreath, J. J., Cody, W. L., Merrell, D. S., and Hendrixson, D. R. (2011). Change is good: variations in common biological mechanisms in the epsilonproteobacterial genera Campylobacter and Helicobacter. Microbiol. Mol. Biol. Rev. 75, 84-132. doi: 10.1128/MMBR.00035-10

Godlewska, R., Wiśniewska, K., Pietras, Z., and Jagusztyn-Krynicka, E. K. (2009). Peptidoglycan-associated lipoprotein (Pal) of Gram-negative bacteria: function, structure, role in pathogenesis and potential application in immunoprophylaxis. FEMS Microbiol. Lett. 298, 1-11. doi: 10.1111/j.15746968.2009.01659.x

Hanahan, D. (1983). Studies on transformation of Escherichia coli with plasmids. J. Mol. Biol. 166, 557-580. doi: 10.1016/S0022-2836(83)80284-8

Hermans, D., Pasmans, F., Messens, W., Martel, A., Van Immerseel, F., Rasschaert, G., et al. (2012). Poultry as a host for the zoonotic pathogen Campylobacter jejuni. Vector Borne Zoonotic Dis. 12, 89-98. doi: 10.1089/vbz.2011.0676

Hermans, D., Van Deun, K., Martel, A., Van Immerseel, F., Messens, W., Heyndrickx, M., et al. (2011a). Colonization factors of Campylobacter jejuni in the chicken gut. Vet. Res. 42:82. doi: 10.1186/1297-9716-42-82

Hermans, D., Van Deun, K., Messens, W., Martel, A., Van Immerseel, F., Haesebrouck, F., et al. (2011b). Campylobacter control in poultry by current intervention measures ineffective: urgent need for intensified fundamental research. Vet. Microbiol. 152, 219-228. doi: 10.1016/j.vetmic.2011. 03.010

Hermans, D., Van Steendam, K., Verbrugghe, E., Verlinden, M., Martel, A., Seliwiorstow, T., et al. (2014). Passive immunization to reduce Campylobacter jejuni colonization and transmission in broiler chickens. Vet. Res. 45:27. doi: 10.1186/1297-9716-45-27

Hodgins, D. C., Barjesteh, N., St Paul, M., Ma, Z., Monteiro, M. A., and Sharif, S. (2015). Evaluation of a polysaccharide conjugate vaccine to reduce colonization by Campylobacter jejuni in broiler chickens. BMC Res. Notes 8:204. doi: 10.1186/s13104-015-1203-Z

Hoppe, S., Bier, F. F., and von Nickisch-Rosenegk, M. (2014). Identification of antigenic proteins of the nosocomial pathogen Klebsiella pneumoniae. PLoS ONE 9:e110703. doi: 10.1371/journal.pone.0110703 
Hu, Y., Huang, J., and Jiao, X. A. (2014). Screening of genes expressed in vivo during interaction between chicken and Campylobacter jejuni. J. Microbiol. Biotechnol. 24, 217-224. doi: 10.4014/jmb.1308.08092

Humphrey, S., Chaloner, G., Kemmett, K., Davidson, N., Williams, N., Kipar, A., et al. (2014). Campylobacter jejuni is not merely a commensal in commercial broiler chickens and affects bird welfare. MBio 5:e1364-14. doi: 10.1128/mBio.01364-14

Jagusztyn-Krynicka, E. K., Laniewski, P., and Wyszyńska, A. (2009). Update on Campylobacter jejuni vaccine development for preventing human campylobacteriosis. Exp. Rev. Vaccines 8, 625-645. doi: 10.1586/erv.09.21

Jaroszewski, L., Rychlewski, L., Li, Z., Li, W., and Godzik, A. (2005). FFAS03: a server for profile-profile sequence alignments. Nucleic Acids Res. 33, W284W288. doi: 10.1093/nar/gki418

Jeon, B., Muraoka, W. T., and Zhang, Q. (2010). Advances in Campylobacter biology and implications for biotechnological applications. Microb. Biotechnol. 3, 242-258. doi: 10.1111/j.1751-7915.2009.00118.x

Jones, D. T. (1999a). GenTHREADER: an efficient and reliable protein fold recognition method for genomic sequences. J. Mol. Biol. 287, 797-815. doi: 10.1006/jmbi.1999.2583

Jones, D. T. (1999b). Protein secondary structure prediction based on position-specific scoring matrices. J. Mol. Biol. 292, 195-202. doi: 10.1006/jmbi.1999.3091

Josefsen, M. H., Andersen, S. C., Christensen, J., and Hoorfar, J. (2015). Microbial food safety: potential of DNA extraction methods for use in diagnostic metagenomics. J. Microbiol. Methods 114, 30-34. doi: 10.1016/j.mimet.2015.04.016

Kaakoush, N. O., Castano-Rodriguez, N., Mitchell, H. M., and Man, S. M. (2015). Global epidemiology of Campylobacter infection. Clin. Microbiol. Rev. 28, 687-720. doi: 10.1128/CMR.00006-15

Kajikawa, A., Zhang, L., Long, J., Nordone, S., Stoeker, L., LaVoy, A., et al. (2012). Construction and immunological evaluation of dual cell surface display of HIV-1 gag and Salmonella enterica serovar Typhimurium FliC in Lactobacillus acidophilus for vaccine delivery. Clin. Vaccine Immunol. 19, 1374-1381. doi: 10.1128/CVI.00049-12

Karplus, K., Karchin, R., Draper, J., Casper, J., Mandel-Gutfreund, Y., Diekhans, M., et al. (2003). Combining local-structure, fold-recognition, and new fold methods for protein structure prediction. Proteins 53(Suppl. 6), 491-496. doi: 10.1002 /prot. 10540

Karplus, P. A., and Schulz, G. E. (1985). Prediction of chain flexibility in proteins - a tool for the selection of peptide antigens. Naturwissenschafren 72, 212-213. doi: 10.1007/BF01195768

Kelley, L. A., MacCallum, R. M., and Sternberg, M. J. (2000). Enhanced genome annotation using structural profiles in the program 3D-PSSM. J. Mol. Biol. 299, 499-520. doi: 10.1006/jmbi.2000.3741

Kobierecka, P., Wyszyńska, A., Maruszewska, M., Wojtania, A., Żylinska, J., Bardowski, J., et al. (2015). Lactic acid bacteria as a surface display platform for Campylobacter jejuni antigens. J. Mol. Microbiol. Biotechnol. 25, 1-10. doi: $10.1159 / 000368780$

Kolaskar, A. S., and Tongaonkar, P. C. (1990). A semi-empirical method for prediction of antigenic determinants on protein antigens. FEBS Lett. 276, 172-174. doi: 10.1016/0014-5793(90)80535-Q

Konkel, M. E., Mead, D. J., and Cieplak, W. Jr. (1996). Cloning, sequencing, and expression of a gene from Campylobacter jejuni encoding a protein (Omp18) with similarity to peptidoglycan-associated lipoproteins. Infect. Immun. 64, 1850-1853.

Korlath, J. A., Osterholm, M. T., Judy, L. A., Forfang, J. C., and Robinson, R. A. (1985). A point-source outbreak of campylobacteriosis associated with consumption of raw milk. J. Infect. Dis. 152, 592-596. doi: 10.1093/infdis/152.3.592

Kosinski, J., Gajda, M. J., Cymerman, I. A., Kurowski, M. A., Pawlowski, M., Boniecki, M., et al. (2005). FRankenstein becomes a cyborg: the automatic recombination and realignment of fold recognition models in CASP6. Proteins 61(Suppl. 7), 106-113. doi: 10.1002/prot.20726

Kurowski, M. A., and Bujnicki, J. M. (2003). GeneSilico protein structure prediction meta-server. Nucleic Acids Res. 31, 3305-3307. doi: $10.1093 / \mathrm{nar} / \mathrm{gkg} 557$

Landete, J. M., Arques, J. L., Peiroten, A., Langa, S., and Medina, M. (2014). An improved method for the electrotransformation of lactic acid bacteria: a comparative survey. J. Microbiol. Methods 105, 130-133. doi: 10.1016/j.mimet.2014.07.022

Łaniewski, P., Kuczkowski, M., Chrząstek, K., Woźniak, A., Wyszyńska, A., Wieliczko, A., et al. (2014). Evaluation of the immunogenicity of Campylobacter jejuni CjaA protein delivered by Salmonella enterica sv. Typhimurium strain with regulated delayed attenuation in chickens. World J. Microbiol. Biotechnol. 30, 281-292. doi: 10.1007/s11274-013-14475

Łaniewski, P., Lis, M., Wyszyńska, A., Majewski, P., Godlewska, R., and JagusztynKrynicka, E. K. (2012). Assessment of chicken protection against Campylobacter jejuni infection by immunization with avirulent Salmonella enterica sv. Typhimurium strain producing Campylobacter CjaD/Pal protein. Vaccine Dev. Ther. 2, 43-50. doi: 10.2147/VDT.S33742

Larsen, J. E., Lund, O., and Nielsen, M. (2006). Improved method for predicting linear B-cell epitopes. Immunome Res. 2:2. doi: 10.1186/1745-7580-2-2

Layton, S. L., Morgan, M. J., Cole, K., Kwon, Y. M., Donoghue, D. J., Hargis, B. M., et al. (2011). Evaluation of Salmonella-vectored Campylobacter peptide epitopes for reduction of Campylobacter jejuni in broiler chickens. Clin. Vaccine Immunol. 18, 449-454. doi: 10.1128/CVI.00379-10

Li, X., Xing, Y., Guo, L., Lv, X., Song, H., and Xi, T. (2014). Oral immunization with recombinant Lactococcus lactis delivering a multi-epitope antigen CTBUE attenuates Helicobacter pylori infection in mice. Pathog. Dis. 72, 78-86. doi: 10.1111/2049-632X.12173

Linding, R., Jensen, L. J., Diella, F., Bork, P., Gibson, T. J., and Russell, R. B. (2003). Protein disorder prediction: implications for structural proteomics. Structure 11, 1453-1459. doi: 10.1016/j.str.2003.10.002

Lundstrom, J., Rychlewski, L., Bujnicki, J., and Elofsson, A. (2001). Pcons: a neuralnetwork-based consensus predictor that improves fold recognition. Protein Sci. 10, 2354-2362. doi: 10.1110/ps.08501

Marelli, B., Perez, A. R., Banchio, C., de Mendoza, D., and Magni, C. (2011). Oral immunization with live Lactococcus lactis expressing rotavirus VP8 subunit induces specific immune response in mice. J. Virol. Methods 175, 28-37. doi: 10.1016/j.jviromet.2011.04.011

Mast, J., and Goddeeris, B. M. (1999). Development of immunocompetence of broiler chickens. Vet. Immunol. Immunopathol. 70, 245-256. doi: 10.1016/S0165-2427(99)00079-3

Meiler, J., and Baker, D. (2003). Coupled prediction of protein secondary and tertiary structure. Proc. Natl. Acad. Sci. U.S.A. 100, 12105-12110. doi: 10.1073/pnas. 1831973100

Meric, G., Yahara, K., Mageiros, L., Pascoe, B., Maiden, M. C., Jolley, K. A., et al. (2014). A reference pan-genome approach to comparative bacterial genomics: identification of novel epidemiological markers in pathogenic Campylobacter. PLoS ONE 9:e92798. doi: 10.1371/journal.pone.00 92798

Muller, A., Thomas, G. H., Horler, R., Brannigan, J. A., Blagova, E., Levdikov, V. M., et al. (2005). An ATP-binding cassette-type cysteine transporter in Campylobacter jejuni inferred from the structure of an extracytoplasmic solute receptor protein. Mol. Microbiol. 57, 143-155. doi: 10.1111/j.13652958.2005.04691.x

Neal-McKinney, J. M., Lu, X., Duong, T., Larson, C. L., Call, D. R., Shah, D. H., et al. (2012). Production of organic acids by probiotic lactobacilli can be used to reduce pathogen load in poultry. PLOS ONE 7:e43928. doi: 10.1371/journal.pone.0043928

Neal-McKinney, J. M., Samuelson, D. R., Eucker, T. P., Nissen, M. S., Crespo, R., and Konkel, M. E. (2014). Reducing Campylobacter jejuni colonization of poultry via vaccination. PLOS ONE 9:e114254. doi: 10.1371/journal.pone.0114254

Newell, D. G., Koopmans, M., Verhoef, L., Duizer, E., Aidara-Kane, A., Sprong, H., et al. (2010). Food-borne diseases - the challenges of 20 years ago still persist while new ones continue to emerge. Int. J. Food Microbiol. 139(Suppl. 1), S3-S15. doi: 10.1016/j.ijfoodmicro.2010.01.021

Oakley, B. B., Lillehoj, H. S., Kogut, M. H., Kim, W. K., Maurer, J. J., Pedroso, A., et al. (2014). The chicken gastrointestinal microbiome. FEMS Microbiol. Lett. 360, 100-112. doi: 10.1111/1574-6968.12608

Ouali, M., and King, R. D. (2000). Cascaded multiple classifiers for secondary structure prediction. Protein Sci. 9, 1162-1176. doi: 10.1110/ps.9.6. 1162

Parker, J. M., Guo, D., and Hodges, R. S. (1986). New hydrophilicity scale derived from high-performance liquid chromatography peptide retention 
data: correlation of predicted surface residues with antigenicity and X-rayderived accessible sites. Biochemistry 25, 5425-5432. doi: 10.1021/bi003 $67 \mathrm{a} 013$

Pawelec, D. P., Korsak, D., Wyszyńska, A. K., Rozynek, E., Popowski, J., and Jagusztyn-Krynicka, E. K. (2000). Genetic diversity of the Campylobacter genes coding immunodominant proteins. FEMS Microbiol. Lett. 185, 43-49. doi: 10.1111/j.1574-6968.2000.tb09038.x

Pawelec, D., Rozynek, E., Popowski, J., and Jagusztyn-Krynicka, E. K. (1997). Cloning and characterization of a Campylobacter jejuni $72 \mathrm{Dz} / 92$ gene encoding a $30 \mathrm{kDa}$ immunopositive protein, component of the $\mathrm{ABC}$ transport system; expression of the gene in avirulent Salmonella typhimurium. FEMS Immunol. Med. Microbiol. 19, 137-150. doi: 10.1111/j.1574-695X.1997.tb01083.x

Pawlowski, M., Gajda, M. J., Matlak, R., and Bujnicki, J. M. (2008). MetaMQAP: a meta-server for the quality assessment of protein models. BMC Bioinformatics 9:403. doi: 10.1186/1471-2105-9-403

Pollastri, G., and McLysaght, A. (2005). Porter: a new, accurate server for protein secondary structure prediction. Bioinformatics 21, 1719-1720. doi: 10.1093/bioinformatics/bti203

Powell, L. F., Lawes, J. R., Clifton-Hadley, F. A., Rodgers, J., Harris, K., Evans, S. J., et al. (2012). The prevalence of Campylobacter spp. in broiler flocks and on broiler carcases, and the risks associated with highly contaminated carcases. Epidemiol. Infect. 140, 2233-2246. doi: 10.1017/S0950268812 000040

Reveneau, N., Geoffroy, M. C., Locht, C., Chagnaud, P., and Mercenier, A. (2002). Comparison of the immune responses induced by local immunizations with recombinant Lactobacillus plantarum producing tetanus toxin fragment $\mathrm{C}$ in different cellular locations. Vaccine 20, 1769-1777. doi: 10.1016/S0264410X(02)00027-0

Robyn, J., Rasschaert, G., Pasmans, F., and Heyndrickx, M. (2015). Thermotolerant Campylobacter during broiler rearing: risk factors and intervention. Compr. Rev. Food Sci. Food Saf. 14, 81-105. doi: 10.1111/1541-4337.12124

Rosenquist, H., Boysen, L., Krogh, A. L., Jensen, A. N., and Nauta, M. (2013). Campylobacter contamination and the relative risk of illness from organic broiler meat in comparison with conventional broiler meat. Int. J. Food Microbiol. 162, 226-230. doi: 10.1016/j.ijfoodmicro.2013.01.022

Rost, B., Yachdav, G., and Liu, J. (2004). The predictprotein server. Nucleic Acids Res. 32, W321-W326. doi: 10.1093/nar/gkh377

Rubin, C. J., Zody, M. C., Eriksson, J., Meadows, J. R., Sherwood, E., Webster, M. T., et al. (2010). Whole-genome resequencing reveals loci under selection during chicken domestication. Nature 464, 587-591. doi: 10.1038/nature 08832

Sahin, O., Luo, N., Huang, S., and Zhang, Q. (2003). Effect of Campylobacterspecific maternal antibodies on Campylobacter jejuni colonization in young chickens. Appl. Environ. Microbiol. 69, 5372-5379. doi: 10.1128/AEM.69.9.5372-5379.2003

Sahin, O., Zhang, Q., Meitzler, J. C., Harr, B. S., Morishita, T. Y., and Mohan, R. (2001). Prevalence, antigenic specificity, and bactericidal activity of poultry anti-Campylobacter maternal antibodies. Appl. Environ. Microbiol. 67, 39513957. doi: 10.1128/AEM.67.9.3951-3957.2001

Sali, A., and Blundell, T. L. (1993). Comparative protein modelling by satisfaction of spatial restraints. J. Mol. Biol. 234, 779-815. doi: 10.1006/jmbi.1993.1626

Sambrook, J., and Russell, D. W. (2001). Molecular Cloning: A Laboratory Manual. New York, NY: Cold Spring Harbor Laboratory Press.

Schokker, D., Veninga, G., Vastenhouw, S. A., Bossers, A., de Bree, F. M., KaalLansbergen, L. M., et al. (2015). Early life microbial colonization of the gut and intestinal development differ between genetically divergent broiler lines. BMC Genomics 16:418. doi: 10.1186/s12864-015-1646-6

Serruto, D., Bottomley, M. J., Ram, S., Giuliani, M. M., and Rappuoli, R. (2012). The new multicomponent vaccine against meningococcal serogroup B, 4CMenB: immunological, functional and structural characterization of the antigens. Vaccine 30(Suppl. 2), B87-B97. doi: 10.1016/j.vaccine.2012.01.033

Shaw, D. M., Gaerthe, B., Leer, R. J., Van Der Stap, J. G., Smittenaar, C., Heijne Den Bak-Glashouwer, M., et al. (2000). Engineering the microflora to vaccinate the mucosa: serum immunoglobulin $G$ responses and activated draining cervical lymph nodes following mucosal application of tetanus toxin fragment C-expressing lactobacilli. Immunology 100, 510-518. doi: 10.1046/j.13652567.2000.00069.x
Shi, J., Blundell, T. L., and Mizuguchi, K. (2001). FUGUE: sequencestructure homology recognition using environment-specific substitution tables and structure-dependent gap penalties. J. Mol. Biol. 310, 243-257. doi: 10.1006/jmbi.2001.4762

Shoaf-Sweeney, K. D., Larson, C. L., Tang, X., and Konkel, M. E. (2008). Identification of Campylobacter jejuni proteins recognized by maternal antibodies of chickens. Appl. Environ. Microbiol. 74, 6867-6875. doi: 10.1128/AEM.01097-08

Silva, J., Leite, D., Fernandes, M., Mena, C., Gibbs, P. A., and Teixeira, P. (2011). Campylobacter spp. as a foodborne pathogen: a review. Front. Microbiol. 2:200. doi: 10.3389/fmicb.2011.00200

Simon, D., and Chopin, A. (1988). Construction of a vector plasmid family and its use for molecular cloning in Streptococcus lactis. Biochimie 70, 559-566. doi: 10.1016/0300-9084(88)90093-4

Soding, J. (2005). Protein homology detection by HMM-HMM comparison. Bioinformatics 21, 951-960. doi: 10.1093/bioinformatics/bti125

Studier, F. W. (2005). Protein production by auto-induction in high density shaking cultures. Protein Expr. Purif. 41, 207-234. doi: 10.1016/j.pep.2005.01.016

Theoret, J. R., Cooper, K. K., Zekarias, B., Roland, K. L., Law, B. F., Curtiss, R. III, et al. (2012). The Campylobacter jejuni Dps homologue is important for in vitro biofilm formation and cecal colonization of poultry and may serve as a protective antigen for vaccination. Clin. Vaccine Immunol. 19, 1426-1431. doi: 10.1128/CVI.00151-12

Tomii, K., and Akiyama, Y. (2004). FORTE: a profile-profile comparison tool for protein fold recognition. Bioinformatics 20, 594-595. doi: 10.1093/bioinformatics/btg474

van Asseldonk, M., Rutten, G., Oteman, M., Siezen, R. J., de Vos, W. M., and Simons, G. (1990). Cloning of usp45, a gene encoding a secreted protein from Lactococcus lactis subsp. lactis MG1363. Gene 95, 155-160. doi: 10.1016/03781119(90)90428-T

van der Vossen, J. M., van der Lelie, D., and Venema, G. (1987). Isolation and characterization of Streptococcus cremoris Wg2-specific promoters. Appl. Environ. Microbiol. 53, 2452-2457.

Villena, J., Oliveira, M. L., Ferreira, P. C., Salva, S., and Alvarez, S. (2011). Lactic acid bacteria in the prevention of pneumococcal respiratory infection: future opportunities and challenges. Int. Immunopharmacol. 11, 1633-1645. doi: 10.1016/j.intimp.2011.06.004

Ward, J. J., McGuffin, L. J., Bryson, K., Buxton, B. F., and Jones, D. T. (2004). The DISOPRED server for the prediction of protein disorder. Bioinformatics 20, 2138-2139. doi: 10.1093/bioinformatics/bth195

Wyszyńska, A., Kobierecka, P., Bardowski, J., and Jagusztyn-Krynicka, E. K. (2015). Lactic acid bacteria-20 years exploring their potential as live vectors for mucosal vaccination. Appl. Microbiol. Biotechnol. 99, 2967-2977. doi: 10.1007/s00253015-6498-0

Wyszyńska, A., Raczko, A., Lis, M., and Jagusztyn-Krynicka, E. K. (2004). Oral immunization of chickens with avirulent Salmonella vaccine strain carrying C. jejuni 72Dz/92 cjaA gene elicits specific humoral immune response associated with protection against challenge with wild-type Campylobacter. Vaccine 22, 1379-1389. doi: 10.1016/j.vaccine.2003.1 1.001

Yan, Y., Yi, G., Sun, C., Qu, L., and Yang, N. (2014). Genome-wide characterization of insertion and deletion variation in chicken using next generation sequencing. PLOS ONE 9:e104652. doi: 10.1371/journal.pone.01 04652

Yang, Z. R., Thomson, R., McNeil, P., and Esnouf, R. M. (2005). RONN: the bio-basis function neural network technique applied to the detection of natively disordered regions in proteins. Bioinformatics 21, 3369-3376. doi: 10.1093/bioinformatics/bti534

Yi, G., Qu, L., Liu, J., Yan, Y., Xu, G., and Yang, N. (2014). Genome-wide patterns of copy number variation in the diversified chicken genomes using next-generation sequencing. BMC Genomics 15:962. doi: 10.1186/1471-216415-962

Zhou, H., and Zhou, Y. (2004). Single-body residue-level knowledge-based energy score combined with sequence-profile and secondary structure information for fold recognition. Proteins 55, 1005-1013. doi: 10.1002/prot. 20007 
Conflict of Interest Statement: The authors declare that the research was conducted in the absence of any commercial or financial relationships that could be construed as a potential conflict of interest.

Copyright (ㄷ) 2016 Kobierecka, Olech, Ksiażek, Derlatka, Adamska, Majewski, Jagusztyn-Krynicka and Wyszyńska. This is an open-access article distributed under the terms of the Creative Commons Attribution License (CC BY). The use, distribution or reproduction in other forums is permitted, provided the original author(s) or licensor are credited and that the original publication in this journal is cited, in accordance with accepted academic practice. No use, distribution or reproduction is permitted which does not comply with these terms. 